\title{
Potential of remote sensing of cirrus optical thickness by airborne spectral radiance measurements at different sideward viewing angles
}

\author{
Kevin Wolf ${ }^{1}$, André Ehrlich ${ }^{1}$, Tilman Hüneke ${ }^{2}$, Klaus Pfeilsticker ${ }^{2}$, Frank Werner $^{1, a}$, Martin Wirth ${ }^{3}$, and \\ Manfred Wendisch ${ }^{1}$ \\ ${ }^{1}$ Leipzig Institute for Meteorology, University of Leipzig, Leipzig, Germany \\ ${ }^{2}$ Institute of Environmental Physics, University of Heidelberg, Heidelberg, Germany \\ ${ }^{3}$ Institute of Atmospheric Physics, German Aerospace Center, Oberpfaffenhofen, Germany \\ ${ }^{a}$ now at: Joint Center for Earth Systems Technology, University of Maryland, Baltimore, MD, USA
}

Correspondence to: Kevin Wolf (kevin.wolf@uni-leipzig.de)

Received: 2 November 2016 - Discussion started: 4 November 2016

Revised: 27 February 2017 - Accepted: 8 March 2017 - Published: 30 March 2017

\begin{abstract}
Spectral radiance measurements collected in nadir and sideward viewing directions by two airborne passive solar remote sensing instruments, the Spectral Modular Airborne Radiation measurement sysTem (SMART) and the Differential Optical Absorption Spectrometer (mini-DOAS), are used to compare the remote sensing results of cirrus optical thickness $\tau$. The comparison is based on a sensitivity study using radiative transfer simulations (RTS) and on data obtained during three airborne field campaigns: the North Atlantic Rainfall VALidation (NARVAL) mission, the MidLatitude Cirrus Experiment (ML-CIRRUS) and the Aerosol, Cloud, Precipitation, and Radiation Interactions and Dynamics of Convective Cloud Systems (ACRIDICON) campaign. Radiative transfer simulations are used to quantify the sensitivity of measured upward radiance $I$ with respect to $\tau$, ice crystal effective radius $r_{\text {eff }}$, viewing angle of the sensor $\theta_{\mathrm{V}}$, spectral surface albedo $\alpha$, and ice crystal shape. From the calculations it is concluded that sideward viewing measurements are generally better suited than radiance data from the nadir direction to retrieve $\tau$ of optically thin cirrus, especially at wavelengths larger than $\lambda=900 \mathrm{~nm}$. Using sideward instead of nadir-directed spectral radiance measurements significantly improves the sensitivity and accuracy in retrieving $\tau$, in particular for optically thin cirrus of $\tau \leq 2$.

The comparison of retrievals of $\tau$ based on nadir and sideward viewing radiance measurements from SMART, miniDOAS and independent estimates of $\tau$ from an additional ac-
\end{abstract}

tive remote sensing instrument, the Water Vapor Lidar Experiment in Space (WALES), shows general agreement within the range of measurement uncertainties. For the selected example a mean $\tau$ of $0.54 \pm 0.2$ is derived from SMART, and $0.49 \pm 0.2$ by mini-DOAS nadir channels, while WALES obtained a mean value of $\tau=0.32 \pm 0.02$ at $532 \mathrm{~nm}$ wavelength, respectively. The mean of $\tau$ derived from the sideward viewing mini-DOAS channels is $0.26 \pm 0.2$. For the few simultaneous measurements, the mini-DOAS sideward channel measurements systematically underestimate $(-17.6 \%)$ the nadir observations from SMART and mini-DOAS. The agreement between mini-DOAS sideward viewing channels and WALES is better, showing the advantage of using sideward viewing measurements for cloud remote sensing for $\tau \leq 1$. Therefore, we suggest sideward viewing measurements for retrievals of $\tau$ of thin cirrus because of the significantly enhanced capability of sideward viewing compared to nadir measurements.

\section{Introduction}

The impact of cirrus on the atmospheric radiative energy budget and the Earth's climate system is uncertain (IPCC, 2013), which is partly due to the limited knowledge about the formation and development of cirrus (Sausen et al., 2005). Until now the fraction that homogeneous or heterogeneous ice nu- 
cleation contributes to the cirrus formation has not been sufficiently quantified (Cziczo et al., 2013). As a result, the evolution of the cirrus microphysical properties during its lifecycle is insufficiently represented in climate models (IPCC, 2013). Furthermore, the influence of cirrus on the Earth's radiation budget is highly variable because it strongly depends on their microphysical properties such as ice crystal number, size and shape (Zhang et al., 1999; Chen et al., 2000; Wendisch et al., 2005, 2007; Yang et al., 2012). In particular, optically thin cirrus ( $\tau \leq 0.03$ ), so called sub-visible cirrus (SVC), is difficult to observe and not well represented in general circulation models (Wiensz et al., 2013). Sub-visible cirrus may extend over large areas (Davis et al., 2010). Therefore, their influence on the energy budget of the Earth can probably not be neglected. Lee et al. (2009) estimated the annually and globally averaged radiative forcing of SVC with $+1 \mathrm{~W} \mathrm{~m}^{-2}$ (warming effect), while the local forcing might be significantly higher. Especially the location and time where SVC occurs determine their radiative effects. Whether SVC heats or cools the atmosphere depends on surface albedo $\alpha$, solar zenith angle $\theta_{0}$ and cirrus optical thickness $\tau$ (Fu and Liou, 1993). In general SVC and cirrus have a heating effect at the top-of-atmosphere (TOA) since the reduction of outgoing infrared radiation usually dominates the cooling effect due to reflection of solar radiation (McFarquhar et al., 2000; Comstock et al., 2002; Davis et al., 2010).

In order to quantify the microphysical and optical properties of SVC, which are needed to determine their radiative effects, more observations of this cloud type are required. As a consequence, several satellite missions and field studies were performed in the past, e.g., by Wang et al. (1996), Winker and Trepte (1998), Sassen et al. (2009), and Jensen et al. (2015), to establish a reliable database on SVC. Airborne in situ measurements by Lampert et al. (2009), Davis et al. (2010), Froyd et al. (2010), and Frey et al. (2011) were utilized to determine ice crystal size and ice crystal shape of SVC. Optical and microphysical parameters derived from these measurements are used in radiative transfer simulations (RTS) and numerical weather prediction and climate modeling (Kärcher, 2002). Despite these efforts, in situ observations of SVC are still scarce and partly accidental due to the challenge of locating SVC. Lampert et al. (2009) sampled an Arctic SVC after it was detected by an airborne lidar. Airborne campaigns dedicated to visible cirrus, e.g., the Contrail, volcano and Cirrus Experiment (CONCERT, Voigt et al., 2010), Mid-Latitude Cirrus (ML-CIRRUS, Voigt et al. (2016)) and tropical cirrus sampled during the Airborne Tropical TRopopause EXperiment (ATTREX) are more frequent (Delanoe et al., 2013; Ehret et al., 2014; Gross et al., 2015; Jensen et al., 2015) and occasionally include observations of SVC. Further international airborne missions like the Tropical Composition, Cloud and Climate Coupling (TC4) (Toon et al., 2010) and the Cirrus Regional Study of Tropical Anvils and Cirrus Layers - Florida Area Cirrus Experiment (CRYSTAL-FACE) mission were conducted, trying to fill the knowledge gap about the formation process and physical properties of tropical cirrus (Jensen et al., 2015).

While satellite observations are suited to study the global coverage of cirrus, their spatial and temporal resolution is still limited and can not resolve the high spatial variability of cirrus. As a consequence the three-dimensional (3-D) radiative effects of different cirrus properties, e.g., $\tau$, ice crystal size and shape, can not be studied using the coarse resolution of satellite remote sensing. Ground-based lidar and radar remote sensing can provide a high temporal resolution but are limited to a fixed location. In situ airborne measurements can provide cirrus properties with both.

For passive remote sensing of cirrus, nadir and sideward viewing observations are available. For nadir measurements $\tau$ and the effective radius $r_{\text {eff }}$ of liquid water droplets can be retrieved by the bi-spectral reflectivity method following Twomey and Seton (1980) and Nakajima and King (1990). Ou et al. (1993), Rolland et al. (2000), and King et al. (2004) adapted this method for ice clouds by introducing some modifications with regard to the thermodynamic phase and crystal shape of the ice particles. Especially due to the crystal shape and low values of $\tau$, cirrus retrievals lead to additional uncertainties compared to liquid water clouds (Eichler et al., 2009; Fricke et al., 2014).

For low $\tau$, the reflected radiation is dominated by the surface reflection below the cirrus. This may introduce a bias in the retrieval of $\tau$ of up to $30 \%$ when $\alpha$ is not accurately known or inhomogeneous (Fricke et al., 2014). Over dark ocean surfaces the radiance $I$ reflected by the cirrus might be weak and can be on the same order of magnitude as Rayleigh scattering in the atmosphere. In addition, inhomogeneities of cirrus lead to three-dimensional (3-D) radiative effects, which may cause a bias in the one-dimensional (1-D) radiative transfer simulations (Eichler et al., 2009). Incorrectly assumed ice crystal shapes also contribute to the retrieval uncertainty. Eichler et al. (2009) investigated the influence of ice crystal shape on derived $\tau$ and $r_{\text {eff. Evaluating }}$ a case study, they concluded that different shapes can lead to relative differences in $\tau$ of up to $70 \%$. In a worst-case scenario, all these effects render retrievals of $\tau$ rather inaccurate. However, observations in the sideward or limb viewing direction and improvements of retrieval techniques may overcome these limitations.

Limb measurements of SVC and cirrus were first introduced and utilized for satellite measurements by Woodbury and McCormick (1986). Since then, several applications based on this method have been developed and are routinely used, e.g., for trace gas measurements (Abrams et al., 1996; Wang et al., 1996; Clerbaux et al., 2003; Bourassa et al., 2005; Fu et al., 2007).

Many trace gas retrievals from aircraft, balloons and satellites are based on ultraviolet (UV)/visible (VIS)/near infrared (IR) sideward viewing measurements in combination with differential optical absorption spectroscopy (DOAS), e.g., performed by Platt and Stutz (2008). Compared to nadir ob- 
servations, radiance measurements in limb or sideward viewing geometry are supposed to be more sensitive to optically thin clouds due to their observation geometry. One recent study was accomplished by Wiensz et al. (2013), who used satellite limb measurements, especially for SVC investigation in the tropical tropopause layer. This data source improved SVC observations with respect to cloud climatology and microphysics.

In the present study, retrievals of $\tau$ are based on simultaneous airborne nadir and sideward viewing observations of cirrus and are compared to elaborate the potential of sideward viewing measurements to derive optical parameters of SVC and optically thin cirrus. This includes a sensitivity study using RTS presented in Sect. 2 and measurements collected on board the High Altitude and LOng range research aircraft (HALO) of the German Aerospace Center (DLR). With a maximum ceiling altitude of around $15 \mathrm{~km}$ HALO is capable of operating in and above SVC and cirrus at mid-latitudes and in polar regions for in situ measurements. The airborne observations are obtained with the Spectral Modular Airborne Radiation measurement sysTem (SMART) (Wendisch et al., 2001) and the Differential Optical Absorption Spectrometer (mini-DOAS) (Hüneke, 2016) both assembled on HALO. The instrumentation is introduced in Sect. 3. Observations from four campaigns, the Mid-Latitude Cirrus experiment (ML-CIRRUS), the Next-generation Aircraft Remote sensing for Validation Studies (NARVAL North and South), and the Aerosol, Cloud, Precipitation, and Radiation Interactions and Dynamics of Convective Cloud Systems (ACRIDICON-CHUVA) (Wendisch et al., 2016) are used to cross-calibrate the two individual instruments in terms of absolute radiance $I$ as presented in Sect. 4. In Sect. 5 an iterative retrieval of $\tau$ is introduced. Utilizing the crosscalibrations together with nadir and sideward viewing measurements of upward $I$, the retrieved results are presented and compared to reference measurements of $\tau$ to emphasize the advantages of sideward viewing observations. Section 6 concludes the study.

\section{Sensitivity of upward radiance measurements in the nadir and sideward viewing directions}

Radiative transfer simulations are performed to investigate the sensitivity of solar radiance measurements in nadir and sideward viewing geometry for SVC and thin cirrus. In this way the potential of sideward viewing versus nadir observations for cirrus cloud parameter detection is examined.

Figure 1 illustrates the measurement geometry. The solar zenith angle $\theta_{0}$ is the angle between zenith and the Sun. The viewing angle $\theta_{\mathrm{V}}$ represents the angle of the sensor viewing direction which is measured between the line-of-sight (LOS) and the nadir direction. For a sensor measuring in nadir $\theta_{\mathrm{V}}$ is $0^{\circ}$ and a sensor orientation close to the horizon is around $\theta_{\mathrm{V}} \approx 90^{\circ}$. The relative solar azimuth angle $\phi$ represents the angle between the LOS and the Sun's direction. It is calculated from the difference in the azimuth angle of the Sun and the azimuth angle of the observation geometry of the optical inlets. For $\phi=0^{\circ}$ the LOS is pointing directly in the direction of the Sun and with $\phi=180^{\circ}$ the LOS is looking away from the Sun.

For the RTS a typical mid-latitude cirrus with a cloud base height of $10 \mathrm{~km}$ and a cloud top height of $12 \mathrm{~km}$ is assumed. This closely represents the cloud situation which is investigated in Sect. 4. Calculations are performed for $\theta_{0}=25,50$ and $75^{\circ}$, representing three different scenarios. The relative solar azimuth angle is set to $\phi=0,90$ and $180^{\circ}$.

The simulations are carried out with the libRadtran 2.0 radiative transfer package (Mayer and Kylling, 2005). The Fortran 77 discrete ordinate radiative transfer solver version 2.0 (FDISORT 2) following Stamnes et al. (2000) is selected to run the simulations. The incoming extraterrestrial solar flux density given by Gueymard (2004) is applied and molecular absorption is calculated using LOWTRAN (Pierluissi and Peng, 1985). A marine aerosol profile is chosen (Shettle, 1989), and for vertical profiles of temperature, humidity, and pressure, a mid-latitude summer atmosphere profile is assumed. A spectral $\alpha$ typically for oceans is chosen according to Clark et al. (2007). To represent ice crystals, a mixture of different particle shapes is used when not otherwise specified. The ice crystal scattering phase function is parameterized according to Yang et al. (2013).

\subsection{Wavelength sensitivity}

Using solar spectral radiation for passive remote sensing purposes, measurements at wavelengths sensitive to scattering and absorption by liquid water droplets and ice crystals are selected. Wavelengths less than $\lambda=900 \mathrm{~nm}$ are applied to retrieve $\tau$ from nadir radiance measurements. Figure $2 \mathrm{a}$ presents simulated upward radiances $I_{\mathrm{RTS}}$ reflected by an optically thin cirrus with $\tau=0.03$ and $r_{\text {eff }}=10 \mu \mathrm{m}$, as well as clear sky radiance as a function of the sensor viewing angle. Radiative transfer simulations for two wavelengths, $\lambda=532 \mathrm{~nm}$ and $\lambda=1180 \mathrm{~nm}$, are carried out. To easily distinguish the different geometries, simulated $I$ in nadir geometry is denoted with $I_{\mathrm{RTS}}^{\mathrm{N}}$, while all geometries deviating from nadir are referred to sideward viewing geometry and are indicated by $I_{\mathrm{RTS}}^{\mathrm{V}}$. The sensitivity $\varepsilon_{\tau}$ is defined by

$\varepsilon_{\tau}=\frac{\mathrm{d} I}{\mathrm{~d} \tau}$.

In general, $I_{\mathrm{RTS}}^{\mathrm{V}}$ increases with increasing $\theta_{\mathrm{V}}$ due to the longer LOS. For a wavelength of $\lambda=532 \mathrm{~nm}$, no difference between cloudy and clear sky conditions is discernible for all $\theta_{\mathrm{V}}$, because Rayleigh scattering by molecules dominates and exceeds the scattering by thin cirrus. Therefore, at $\lambda=532 \mathrm{~nm} \mathrm{SVC}$ with $\tau=0.03$, which is presented in the simulations, can not be detected. Conversely, for 

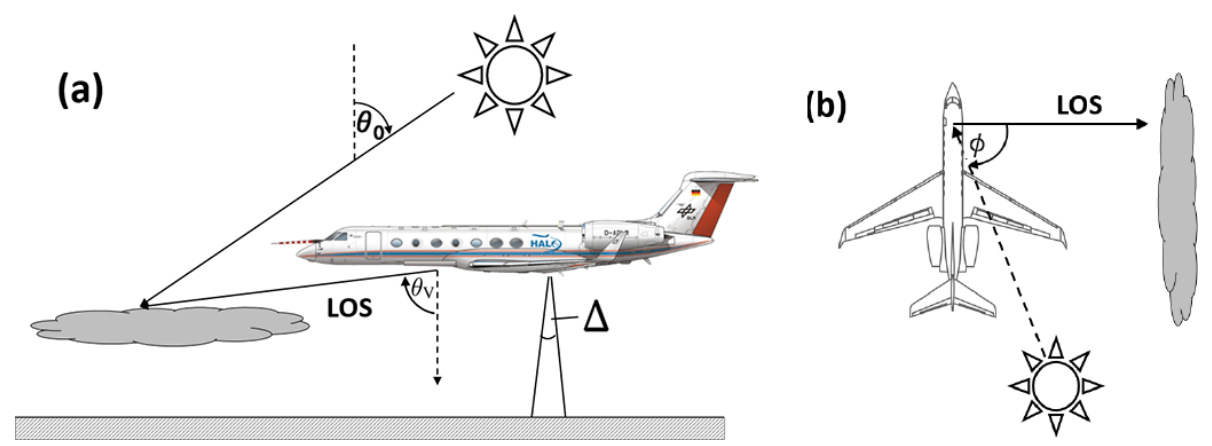

Figure 1. Illustration of the measurement geometry. (a) shows the side view with solar zenith angle $\theta_{0}$ and the viewing angle $\theta_{\mathbf{V}}$. The opening angle of the nadir looking radiance sensor of SMART is indicated by $\Delta$. The top view (b) shows the definition of the relative solar azimuth angle $\phi$ between the line-of-sight (LOS) and the Sun.
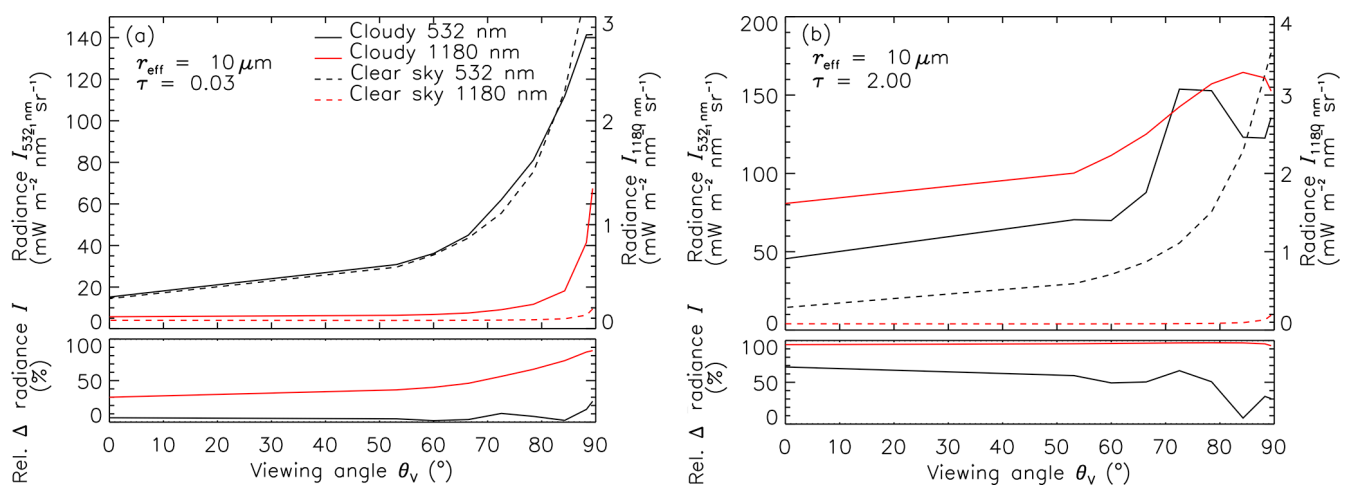

Figure 2. Simulated upward radiance $I_{\mathrm{RTS}}$ at $\lambda=532 \mathrm{~nm}$ and $\lambda=1180 \mathrm{~nm}$ for the cloudy (solid line) and clear sky (dashed line) cases as a function of the viewing angle $\theta \mathrm{V}$. The left plot shows simulations for a SVC with $\tau=0.03$ (a) and the right plot presents the simulations for a thick cirrus with $\tau=2.0$ (b). In the corresponding lower plots the relative difference between cloud and clear sky atmosphere with respect to the cloudy atmosphere is shown.

$\lambda=1180 \mathrm{~nm}$ separation between the simulations with and without cirrus at large viewing angles for $\theta_{\mathrm{V}}>70^{\circ}$ is present because the reflected $I_{\mathrm{RTS}}^{\mathrm{V}}$ is increased due to a larger LOS. At $\lambda=1180 \mathrm{~nm}$ wavelength Rayleigh scattering is comparably weak and does not significantly contribute to the reflected radiation. In the nadir direction, a detection of SVC is not possible due to low $\tau$ and the overwhelming backscattering from the ground.

For comparison, simulations of a thicker cirrus with $\tau=2.0$ are presented in Fig. $2 \mathrm{~b}$. Here, the influence of the Rayleigh scattering at $\lambda=532 \mathrm{~nm}$ is reduced and a distinction between cloudy and clear-sky becomes possible. However, the relative difference between cloudy and clear-sky conditions is still more pronounced at $\lambda=1180 \mathrm{~nm}$.

The RTS suggest that sideward viewing observations at near-IR wavelengths $(\lambda>900 \mathrm{~nm})$ are more suitable for the detection of SVC and cirrus. As a result the retrieval in Sect. 4 is performed at 1180 and $1600 \mathrm{~nm}$ wavelengths in the IR region, which are sensitive to $\tau$ and $r_{\mathrm{eff}}$ and not disturbed by Rayleigh scattering.

\subsection{Optical thickness and viewing angle}

In general, back-scattered radiation by clouds increases with increasing $\tau$. This sensitivity (see Eq. 1) is the basis of most retrieval algorithms of cloud optical properties. To quantify how $\varepsilon_{\tau}$ is effected by $\theta_{\mathrm{V}}$ of the sensor, RTS are performed for a set of different $\theta_{\mathrm{V}}$ ranging between $\theta_{\mathrm{V}}=0^{\circ}$ (nadir) and $\theta \mathrm{v}=90^{\circ}$ (sideward viewing). Cirrus optical thickness is varied in the range of $\tau=0.03-4$ covering various kinds of cirrus clouds.

The first simulations presented in Fig. 3 display simulated $I_{\mathrm{RTS}, 1180}$ at $\lambda=1180 \mathrm{~nm}$ wavelength for two different $\theta_{0}=25^{\circ}$ (a) and $\theta_{0}=75^{\circ}$ (b) as a function of $\tau$. For each scenario, $\varepsilon_{\tau}$ is calculated and given in the lower panels of Fig. 3. Simulations for nadir geometry are represented by solid black lines. Results for sideward viewing sensor orientations are shown by dashed $\left(\theta_{\mathrm{V}}=53^{\circ}\right)$ and gray $\left(\theta_{\mathrm{V}}=78^{\circ}\right)$ lines. All scenarios show an increase in $I_{\mathrm{RTS}}^{\mathrm{V}}$ for increasing $\tau$, which results from enhanced reflection.

Due to the apparently longer LOS for both $\theta_{0}$, sideward viewing sensor orientations yield larger $\varepsilon_{\tau}$ of simulated $I_{\mathrm{RTS}}^{\mathrm{V}}$ as compared to the nadir geometry for cirrus clouds with 

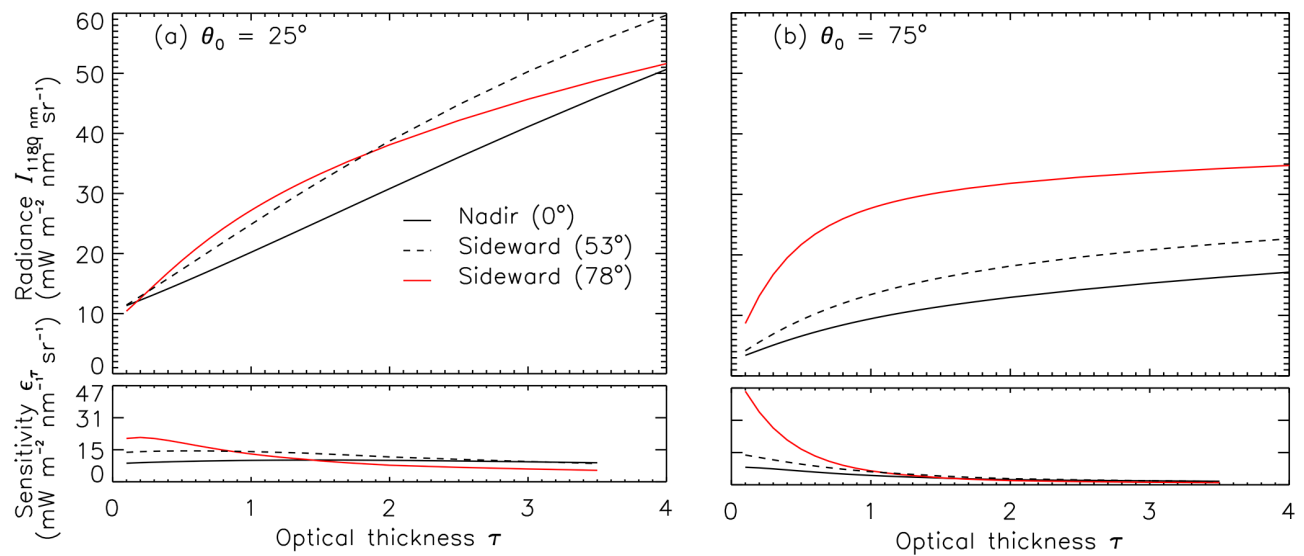

Figure 3. Simulated radiance $I_{\mathrm{RT}, 1180}$ for three different sensor orientations as a function of cirrus optical thickness $\tau$. Results for solar zenith angles of $\theta_{0}=25^{\circ}$ (a) and $\theta_{0}=75^{\circ}$ (b) are displayed. The sensitivity $\varepsilon_{\tau}$ is given in the lower panels.

$\tau \leq 1$ which includes SVC. This indicates that sideward measurements are most suited to retrieve $\tau$ below 1 and for the detection of SVC. The almost linear increase in the nadir radiance $I_{\mathrm{RTS}}^{\mathrm{N}}$ indicates a constant $\varepsilon_{\tau}$ for the investigated range of $\tau$ and $\theta_{0}$. For $\tau \geq 1$ the sensitivity of sideward viewing observations is in the same range compared to nadir measurements or slightly lower depending on the combination of $\theta_{0}$ and $\theta_{\mathrm{v}}$.

For low $\tau$ and a high Sun, the highest $\varepsilon_{\tau}$ is given for the sideward viewing geometry $\left(\theta_{\mathrm{V}}=78^{\circ}\right)$ for $\tau \leq 1$. A similar pattern emerges for low Sun $\left(\theta_{0}=75^{\circ}\right)$, resulting in larger $\varepsilon_{\tau}$ and a steep decrease for increasing $\tau$. It shows that $\varepsilon_{\tau}$ decreases with $\tau$ and for $\tau<2$ drops below $\varepsilon_{\tau}$ of nadir measurements. The sensitivity of $I$ with respect to $\tau$ can also be interpreted in terms of the uncertainty of retrieved $\tau$ related to an initial uncertainty in measured $I$. The higher the $\varepsilon_{\tau}$, the weaker the impact of uncertainties in the measurements on the uncertainties of the retrieved $\tau$. As shown in Fig. 3b, a high $\varepsilon_{\tau}$ is calculated for $I_{\mathrm{RTS}, 1180}$ for $\tau \leq 1$ and indicates a lower measurement uncertainty. Therefore, sideward viewing observations at $\lambda=1180 \mathrm{~nm}$ allow a more accurate determination of $\tau$ compared to nadir observations for optically thin clouds with $\tau \leq 1$.

In a second step, the influence of $\phi$ is investigated on $I_{\mathrm{RTS}}^{\mathrm{V}}$ in respective simulations.

Figure 4 shows $\varepsilon_{\tau}$ for a wide range of $\theta_{\mathrm{V}}$ between $0^{\circ}$ and $90^{\circ}$ and $\phi$ between $0^{\circ}$ and $180^{\circ}$ for two clouds with $\tau=0.1$ and $\tau=2$ and two different solar zenith angles (SZA) of $\theta_{0}=25^{\circ}$ and $\theta_{0}=75^{\circ}$. The graphs represent $\varepsilon_{\tau}$ in units of $\mathrm{mW} \mathrm{m}{ }^{-2} \mathrm{~nm}^{-1} \mathrm{sr}^{-1}$ for different $\phi$ as a function of $\theta_{\mathrm{v}}$.

For $\tau=0.1$ and $\theta_{0}=25^{\circ}$ (Fig. $4 \mathrm{a}$ ), $\varepsilon_{\tau}$ ranges between 5 and $66 \mathrm{~mW} \mathrm{~m}^{-2} \mathrm{~nm}^{-1} \mathrm{sr}^{-1}$. For larger $\theta_{\mathrm{V}}$ (sideward viewing observations), $\varepsilon_{\tau}$ increases significantly, reaching the maximum for $\theta \mathrm{v}=90^{\circ}$ and $\phi=0^{\circ}$. Observations under these angles are better suited in comparison to other angle combinations as they enable us to achieve the largest possible $\varepsilon_{\tau}$ and reduced relative measurement errors, which results in increased retrieval accuracy.

A similar pattern is derived for simulations assuming a lower Sun $\left(\theta_{0}=75^{\circ}\right)$ as shown in Fig. 4b. Compared to $\theta_{0}=25^{\circ}$ the increase in $\varepsilon_{\tau}$ for $\theta_{\mathrm{V}}=90^{\circ}$ and $\phi=0^{\circ}$ is stronger, reaching values of $377 \mathrm{~mW} \mathrm{~m}^{-2} \mathrm{~nm}^{-1} \mathrm{sr}^{-1}$, while for all other geometries $\varepsilon_{\tau}$ almost remains constant at the same magnitude, reaching $80 \mathrm{~mW} \mathrm{~m}^{-2} \mathrm{~nm}^{-1} \mathrm{sr}^{-1}$. Additionally, the maximum $\varepsilon_{\tau}$ is more concentrated on a single combination of $\theta_{\mathrm{V}}$ and $\phi$ represented by the high peak for $\phi=0$ compared to all other $\phi$. Therefore, measurements in the range of these angles are recommended to achieve high values of $\varepsilon_{\tau}$ for reasonable retrievals of $\tau$.

Figure $4 \mathrm{c}$ shows the simulated $\varepsilon_{\tau}$ for clouds of $\tau=2, \theta_{0}=$ $25^{\circ}$ and a wide range of geometries. Compared to the optically thin cirrus, the maximum of $\varepsilon_{\tau}$ is reduced for optical thick cirrus, not exceeding a value of $15 \mathrm{~mW} \mathrm{~m}^{-2} \mathrm{~nm}^{-1} \mathrm{sr}^{-1}$ and shifted to smaller $\theta_{0}$. While sideward viewing measurements are predicted to become saturated for thick clouds, for low $\tau$ the optimal $\theta_{\mathrm{V}}$ is about $\theta_{\mathrm{V}}=60^{\circ}$, with the largest $\varepsilon_{\tau}$ occurring for $\phi$ between 0 and $60^{\circ}$. Respective simulations for $\tau=2, \theta_{0}=75^{\circ}$ (low Sun) are presented in Fig. 4d. Here, the maximum of $\varepsilon_{\tau}$ is small, with $5 \mathrm{~mW} \mathrm{~m}^{-2} \mathrm{~nm}^{-1} \mathrm{sr}^{-1}$ at $\theta_{\mathrm{V}}$ and $\phi=0$ compared to all other simulations varying $\tau$ and $\theta_{0}$.

The RTS show that the choice of the best viewing geometry (nadir or sideward viewing observations) strongly depends on $\tau$ and $\phi$. In order to probe a large range of cirrus with sufficiently large retrieval sensitivity, measurements in different viewing directions, at least in the nadir and sideward viewing directions depending on $\tau$ and $\theta_{0}$, are recommended. Measurements in sideward viewing geometry are strongly dependent on $\theta_{\mathrm{V}}$, especially around $\theta_{\mathrm{V}}=90^{\circ}$. In order to avoid spurious results by mispointing with the sensor, a careful alignment of the optical sensor and an accurate determination is required. Considering these findings, the retrieval of $\tau$ in Sect. 4 is performed for $\theta_{\mathrm{V}} \leq 60^{\circ}$ only. 

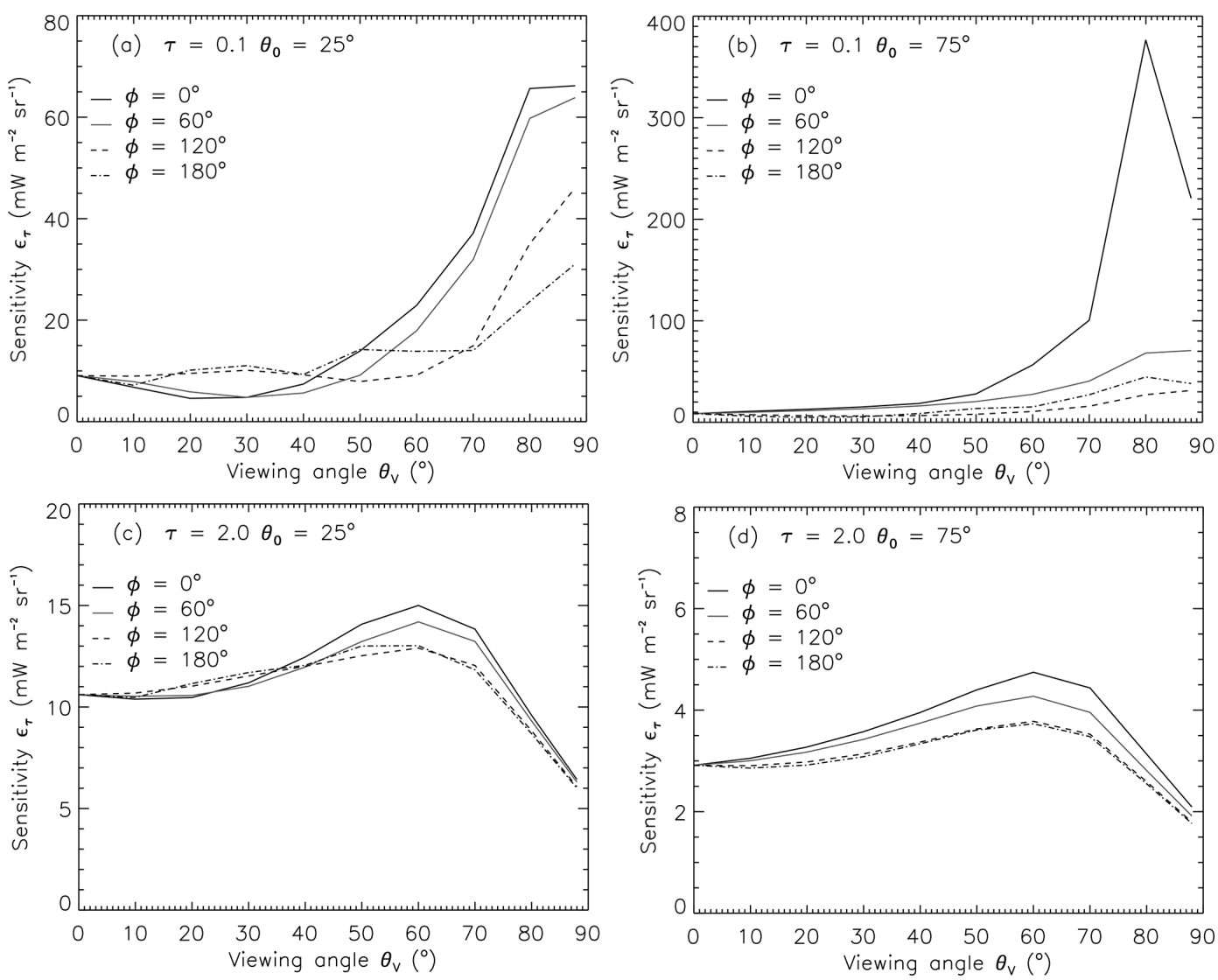

Figure 4. Sensitivity $\varepsilon_{\tau}$ at $1180 \mathrm{~nm}$ in units of $\mathrm{mW} \mathrm{m}^{-2} \mathrm{sr}^{-1}$ as a function of viewing angle $\theta \mathrm{V}$ and relative solar azimuth angle $\phi$ for cirrus optical thickness $\tau$ and solar zenith angle $\theta_{0}$. Panel (a) for $\tau=0.1, \theta_{0}=25^{\circ}$, Panel (b) for $\tau=0.1, \theta_{0}=75^{\circ}$, and Panel (c) for $\tau=2$, $\theta_{0}=25^{\circ}$ in (c) and (d) for $\tau=2, \theta_{0}=75^{\circ}$. Different scales of the plots have to be considered.

\subsection{Influence of surface albedo}

The influence of $\alpha$ on the retrieval of cloud optical properties derived by passive remote sensing using the Moderate Resolution Imaging Spectroradiometer (MODIS) was investigated by Rolland and Liou (2001). They showed that retrievals of clouds with $\tau<0.5$ are strongly influenced by variations in $\alpha$. Based on RTS, Fricke et al. (2014) concluded that $I^{\mathrm{N}}$ measured in the nadir direction strongly depends on the underlying surface reflectivity and that uncertainties in assumed $\alpha$ may cause errors of up to $50 \%$ in the retrieval of $\tau$.

In order to quantify and compare the influence of $\alpha$ on $I$ measured in different $\theta_{\mathrm{V}}$ and nadir directions, RTS are performed. To cover the natural variability of surfaces ranging from ocean surface to ice-covered regions, $\alpha$ is varied between $\alpha=0.1$ and $\alpha=0.9$. Figure 5 shows simulated $I_{\mathrm{RTS}, 1180}^{\mathrm{V}}$ at $\lambda=1180 \mathrm{~nm}$ wavelength for two clouds with $\tau=0.1$ and $\tau=2$ and both observation geometries.

In general, the reflected $I$ increases with increasing $\alpha$. The stronger the increase, the more strongly the measurements are effected by $\alpha$. For both observation geometries, the steep-

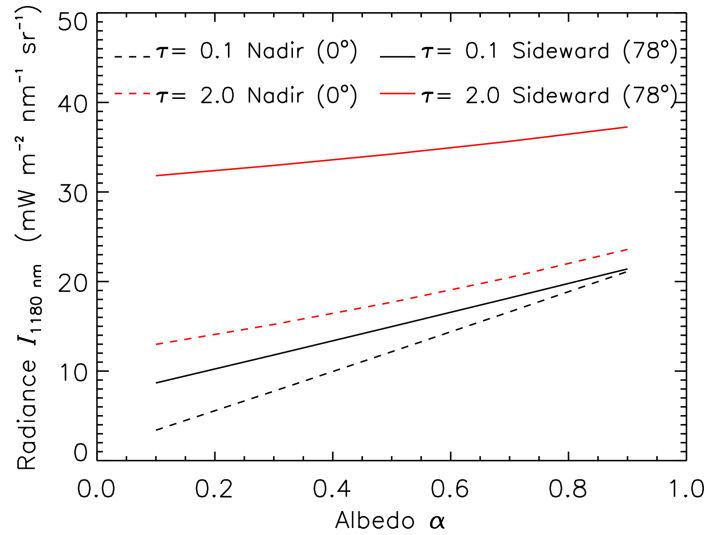

Figure 5. Influence of the surface albedo $\alpha$ on the measured upward radiance $I_{\mathrm{RTS}, 1180}^{\mathrm{V}}$ at $\lambda=1180 \mathrm{~nm}$ as a function of cirrus optical thickness $\tau$ and sensor orientation $\theta_{\mathrm{V}}$.

est derivative,

$$
\gamma=\frac{\mathrm{d} I}{\mathrm{~d} \alpha}
$$


Table 1. Relative difference in $I_{\mathrm{RTS}, 1180 \mathrm{~nm}}$ for surface albedo $\alpha=0.1$ and $\alpha=0.9$ for different viewing angles $\theta_{\mathrm{V}}$ and optical thickness $\tau$.

\begin{tabular}{llll}
\hline & \multicolumn{3}{c}{ cirrus optical thickness } \\
\cline { 2 - 4 } viewing angle & $\tau=0.1$ & $\tau=0.5$ & $\tau=2$ \\
\hline$\theta_{\mathrm{V}}=0^{\circ}$ & $84 \%$ & $69 \%$ & $44 \%$ \\
$\theta \mathrm{V}=78^{\circ}$ & $58 \%$ & $29 \%$ & $14 \%$ \\
\hline
\end{tabular}

is obtained for the thin cirrus with $\tau=0.1$. In general for increasing $\tau$ of thick clouds, $\alpha$ becomes less important for I compared to cirrus clouds with lower $\tau$. To quantify the impact of changes in $\alpha$, the relative difference between $I_{\text {RTS }}$ simulated for $\alpha=0.1$ and $\alpha=0.9$ is calculated for each case and presented in Table 1. Maximum differences of up to $84 \%$ are noticeable in nadir geometry for clouds of $\tau=0.1$. Optically thick clouds show lower dependencies on $\alpha$ due to the increased contribution of radiation reflected by the cirrus. Comparing nadir and sideward viewing geometries, the simulations show a smaller $\gamma$ for sideward viewing observations independent of $\alpha$. The relative difference in $I_{\mathrm{RTS}}^{\mathrm{V}}$ for $\tau=2$ between $\alpha=0.1$ and $\alpha=0.9$ is reduced to $14 \%$. This indicates that $I$ measured in sideward viewing geometry is less influenced by changes in $\alpha$ (e.g., Oikarinen, 2002). This difference in $I$ is most pronounced for optically thin clouds where the surface contribution to measured $I$ is relatively large. Under unknown or variable surface albedo conditions, observations in the sideward viewing direction are favored over those in the nadir direction when retrieving the optical properties of thin cirrus.

\subsection{Crystal shape sensitivity}

By changing the ice crystal shape in the RTS (similar cloud to that described above), the sensitivity of $I$ with respect to the ice crystal scattering phase function is investigated and compared for different viewing geometries. Ice crystals with shapes of columns, droxtals and plates are chosen and implemented in the simulations to cover the natural variability of cirrus based on the ice crystal single scattering properties provided by Yang et al. (2013). Most cirrus are composed of a mixture of ice crystal shapes (Pruppacher and Klett, 1997). Particle shape dependent scattering effects are lower due to smoothing over different crystal shapes. Therefore, an ice crystal mixture as given by Baum et al. (2005) is included in the simulations and serves as a reference. This is denoted with the acronym "GHM" further on. The simulated $I_{\mathrm{RTS}, 1180}^{\mathrm{V}}$ as a function of $\theta_{\mathrm{V}}$ is presented in Fig. 6.

The increase in $I_{\mathrm{RTS}, 1180}^{\mathrm{V}}$ with increasing $\theta_{\mathrm{V}}$ is significantly influenced by the ice crystal shape. In the simulated cases, droxtals and the GHM ice crystal mixture show a larger increase in $I_{\mathrm{RTS}, 1180}^{\mathrm{V}}$ with increasing $\theta_{\mathrm{V}}$ than columns and plates. While in nadir geometry $\left(\theta_{\mathrm{V}}=0^{\circ}\right)$, columns

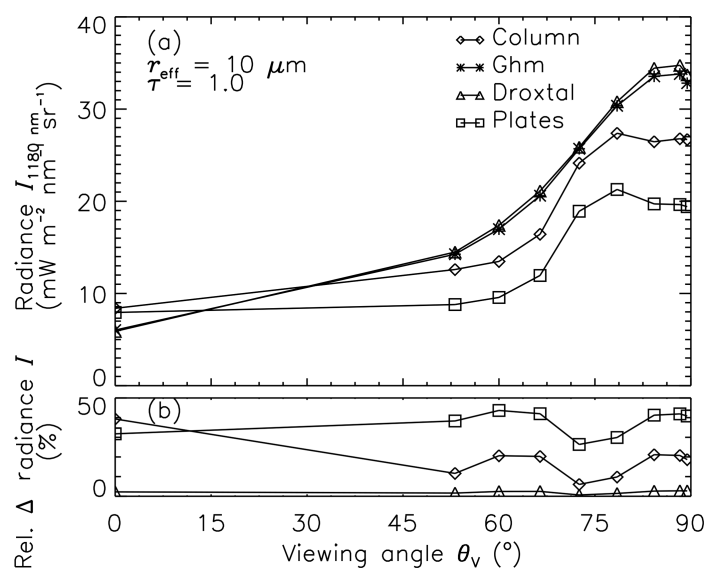

Figure 6. Simulated radiance $I_{\mathrm{RTS}, 1180}^{\mathrm{V}}$ at $\lambda=1180 \mathrm{~nm}$ wavelength for different ice crystal shapes as a function of the viewing angle $\theta_{\mathrm{V}}$ of the sensor (a). In Panel (b) the relative differences in simulated radiance with respect to the reference shape "Ghm" are presented for the other three ice crystal shapes.

and plates have a higher $I_{\mathrm{RTS}, 1180}^{\mathrm{V}}$ than droxtals and GHM, $I_{\mathrm{RTS}, 1180}^{\mathrm{V}}$ measured at viewing angles $\theta \mathrm{v}>50^{\circ}$ is higher for droxtals and the GHM crystal mixture. The spatial distribution obtained for droxtals results from the enhanced forward and reduced sideways scattering compared to other crystal shapes.

For simulations in the nadir direction the relative difference between the lowest (droxtals) and highest (columns) $I_{\mathrm{RTS}, 1180}^{\mathrm{N}}$ differs by up to $41.5 \%$ of the absolute radiance of $6.1 \mathrm{~mW} \mathrm{~m}^{-2} \mathrm{~nm}^{-1} \mathrm{sr}^{-1}$ obtained by the "GHM" crystal mixture.

For sideward viewing observations the relative and absolute changes in $I_{\mathrm{RTS}, 1180}^{\mathrm{V}}$ are even larger between $\theta_{\mathrm{V}}=60^{\circ}$ and $\theta_{\mathrm{V}}=90^{\circ}$. With increasing $\theta_{\mathrm{V}}$ the differences in $I_{\mathrm{RTS}, 1180}^{\mathrm{V}}$ increase up to a maximum of $43.5 \%$ at $\theta \mathrm{V}=78^{\circ}$ between droxtals and plates with respect to the absolute value of $33.8 \mathrm{~mW} \mathrm{~m}^{-2} \mathrm{~nm}^{-1} \mathrm{sr}^{-1}$ for GHM.

The simulations show that the relative change in simulated $I_{\mathrm{RTS}, 1180}^{\mathrm{V}}$ due to ice crystal shape effects increases with $\theta \mathrm{v}$. Therefore, for cirrus of low $\tau$ the interpretation of sideward viewing observations relies even more strongly on a correct assumption of ice crystal shape than nadir observations. Multiangular observations covering the angular pattern (Fig. 6) may provide sufficient information to retrieve ice crystal shape as proposed by Schäfer et al. (2013).

\section{Airborne measurements}

Simultaneous airborne measurements of $I$ in nadir and sideward viewing geometry were conducted during four campaigns using HALO. During NARVAL shallow convection in the North Atlantic trade-wind region of the northern Atlantic (NARVAL South, December 2013) and cloud systems asso- 


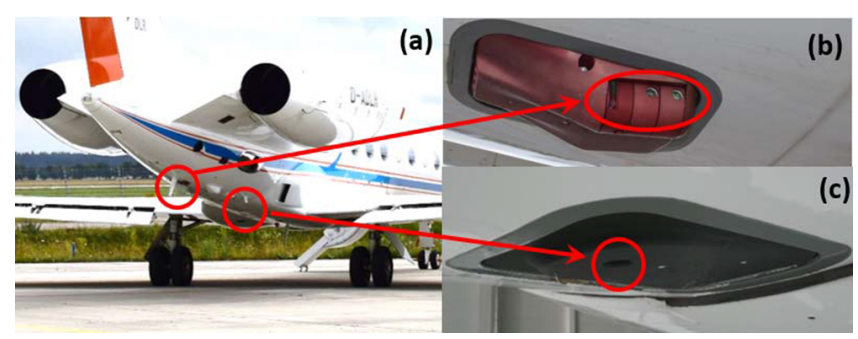

Figure 7. (a) Optical inlets of mini-DOAS (b) and SMART (c) mounted at the lower aircraft fuselage.

ciated with the North Atlantic mid-latitude stormtrack (NARVAL North, January 2014) were probed (Klepp et al., 2014). During the ML-CIRRUS campaign natural and contrail cirrus in the mid-latitudes were investigated in March and April 2014 (Voigt et al., 2016). Deep convective clouds were observed during the Aerosol, Cloud, Precipitation, and Radiation Interactions and Dynamics of Convective Cloud Systems (ACRIDICON-CHUVA) mission in September 2015 (Wendisch et al., 2016).

During these missions, a suite of different active and passive remote sensing instruments was operated on board HALO, including passive solar radiance measurements by SMART (Wendisch et al., 2016; Ehrlich et al., 2008) and the mini-DOAS (Hüneke, 2016). While SMART measured radiometrically calibrated radiance $I_{\mathrm{S}}^{\mathrm{N}}$ in the nadir direction, the mini-DOAS instrument simultaneously measures in the nadir and varying sideward viewing directions in UV/VIS/IR wavelength ranges. The mini-DOAS measurements are traditionally analyzed by applying the DOAS technique. DOAS relies on an analysis of intensity ratios of two spectroscopic observations made under largely different atmospheric conditions. By exploiting ratios of $I$, DOAS measurements are inherently radiometrically calibrated in a relative but not absolute sense. Therefore no absolute radiometric calibration for $I$ for the mini-DOAS is available. In addition to the two passive sensors, active lidar measurements with the Water Vapor Lidar Experiment in Space (WALES) were performed during NARVAL and ML-CIRRUS.

In Fig. $7 \mathrm{a}$ the position of the apertures at the aircraft fuselage is indicated. The optical inlets of mini-DOAS and SMART for upward radiation are shown in Fig. $7 \mathrm{~b}$ and c, respectively.

\subsection{The SMART instrument}

Depending on the configuration, SMART measures spectral upward $F_{\mathrm{S}, \lambda}^{\uparrow}$ and downward irradiance $F_{\mathrm{S}, \lambda}^{\downarrow}$, as well as spectral upward radiance $I_{\mathrm{S}}^{\mathrm{N}}$. The system is extensively described in Wendisch et al. (2001) and Ehrlich et al. (2008). In this paper the focus is on $I_{\mathrm{S}}^{\mathrm{N}}$ measurements which are available for the four HALO missions introduced above.
Table 2. Individual sources of uncertainty and total uncertainties for the upward radiance $I_{\mathrm{S}, 1180}^{\mathrm{N}}$ at a wavelength of $\lambda=1180 \mathrm{~nm}$.

\begin{tabular}{lll}
\hline & Source of uncertainty & $\lambda=1180 \mathrm{~nm}$ \\
\hline$I_{\mathrm{S}, 1180}^{\mathrm{N}}$ & Spectral calibration & $<1 \%$ \\
& Radiometric calibration & $8.5 \%$ \\
& Signal-to-noise ratio & $11.6 \%$ \\
& Transfer calibration & $<1.1 \%$ \\
\hline & Total & $14.5 \%$ \\
\hline
\end{tabular}

To cover almost the entire solar spectral range, SMART measures $I_{\mathrm{S}}^{\mathrm{N}}$ with two separate spectrometers, one for the VIS range from $\lambda=300 \mathrm{~nm}$ to $\lambda=1000 \mathrm{~nm}$ and a second one for sampling the IR range from $\lambda=900 \mathrm{~nm}$ to $\lambda=2200 \mathrm{~nm}$. By merging the spectra, about $97 \%$ of the solar spectrum is covered (Bierwirth et al., 2009, 2010). The spectral resolution defined by the full width at half maximum (FWHM) is $8-10 \mathrm{~nm}$ for the IR spectrometer and $2-3 \mathrm{~nm}$ for the VIS spectrometer.

The radiance optical inlet of SMART has an opening angle of $\Delta=2^{\circ}$ and a sampling time of $0.5 \mathrm{~s}$. Considering aircraft groundspeed and the distance of $500 \mathrm{~m}$ between the cloud and the aircraft the resulting footprint is about $18 \times 110 \mathrm{~m}$ for an individual $I_{\mathrm{S}}^{\mathrm{N}}$ measurement. For a distance of $1000 \mathrm{~m}$ between sensor and cloud the footprint increases to $35 \times 220 \mathrm{~m}$.

Prior to each campaign SMART was radiometrically calibrated in the laboratory using certified calibration standards traceable to NIST and by secondary calibration using a travelling standard during the operation on HALO. The total measurement uncertainty of $I_{\mathrm{S}}^{\mathrm{N}}$ is about $5.4 \%$ for the VIS and $14.5 \%$ for the IR range which consist of individual errors due to the spectral calibration, the spectrometer noise and dark current, the radiometric calibration and the transfer calibration (Brückner et al., 2014). In Table 2 the contributions of each individual source of uncertainty is given for measurements at $\lambda=1180 \mathrm{~nm}$ wavelength. The main uncertainty results from the signal-to-noise ratio (SNR) and the calibration standard, while spectral and transfer calibration errors are almost negligible. Averaging a time series of measurements will reduce the contribution of sensor noise to the signal.

\subsection{The mini-DOAS instrument}

The mini-DOAS is a passive airborne remote sensing system originally designed to retrieve vertical profiles of trace gases, aerosol and cloud particles (Hüneke, 2016). The analysis is based on the DOAS technique that applies least square retrievals to the spectral shape of the observed upward radiance $I_{\mathrm{mD}}^{\mathrm{V}}$ by the mini-DOAS in sideward viewing channels (Platt and Stutz, 2008). Spectral absorption bands of molecules and particles are measured at moderate spectral resolution $(\mathrm{FWHM}=0.47,1.2$ and $10 \mathrm{~nm}$ for the UV, VIS and IR, re- 
spectively) to quantify the absorption of solar radiation by trace gases along the light path. DOAS measurements are primarily used to infer trace gas concentrations and associated photochemistry in the atmosphere. Here, measured $I_{\mathrm{mD}}^{\mathrm{V}}$ are employed for the remote sensing of clouds.

The mini-DOAS is designed as a compact, lightweight and robust system to be operated aboard HALO. The instrument consists of six telescopes which are connected via fiber bundles to six optical spectrometers. One set of the optical inlets is fixed in the nadir configuration, while the other telescopes can be tilted between $\theta_{\mathrm{V}}=0^{\circ}$ and $\theta_{\mathrm{V}}=90^{\circ}$. Two sets of three different spectrometers are applied to cover the UV spectral range from 310 to $440 \mathrm{~nm}$ (FWHM $0.5 \mathrm{~nm}$ ), the VIS range from 420 to $650 \mathrm{~nm}$ (FWHM $1 \mathrm{~nm}$ ) and the IR range from 1100 to $1680 \mathrm{~nm}$ (FWHM $10 \mathrm{~nm}$ ). In the UV and VIS range, charged-coupled device (CCD) sensors are used as detectors. The detection in the IR range is performed by photo diode arrays (PDAs).

The telescopes are mounted on an aperture plate at the lower side of the aircraft fuselage. The scanning telescopes have rectangular fields-of-view of about $0.6^{\circ}$ in vertical direction and $3^{\circ}$ in horizontal direction. During scanning measurements the telescopes are directed to the starboard side of the aircraft. Changes in aircraft roll angles are compensated within $0.2^{\circ}$. The orientation of the nadir telescope is kept fix with respect to the aircraft major axis. Therefore no compensation of the aircraft roll angle is performed.

The evacuated spectrometer housing is immersed into an isolated water/ice tank to ensure a constant temperature and pressure of the spectrometers independent of changing outside conditions. Evacuation of the housing and temperature stabilization is necessary to guarantee a stable optical imaging, which is indispensable for DOAS applications. A spectral calibration of the spectrometers ensures that wavelength shifts are less than $0.05 \mathrm{~nm}$.

\subsection{The WALES instrument}

The Water Vapor Lidar Experiment in Space Demonstrator (WALES) is an airborne Differential Absorption Lidar (DIAL) with additional aerosol and cloud detection capabilities operated on the German research aircraft Falcon and HALO (Wirth et al., 2009).

For particle detection WALES has two backscatter and depolarization channels at $\lambda=532 \mathrm{~nm}$ and $\lambda=1064 \mathrm{~nm}$ wavelength and an additional high spectral resolution lidar (HSRL) channel at $\lambda=532 \mathrm{~nm}$ (Esselborn et al., 2008). The HSRL channel allows the retrieval of the backscatter coefficient of clouds at $\lambda=532 \mathrm{~nm}$ without assumptions about the phase function of the cloud particles. Unfortunately, larger cirrus particles usually show a pronounced forward scattering peak, which may contain a significant fraction of the scattered energy. This may lead to an underestimation of $\tau$ calculated from the individual particle extinction cross sections (see, e.g., Platt, 1981). The optical thickness data pre- sented in this paper are corrected for the forward scattering effect following the algorithm proposed by Eloranta (1998). To apply this correction scheme, an $r_{\text {eff }}$ is assumed, which determines the width of the forward scattering peak. The best compensation of the multiple scattering decay below the cloud is found for $r_{\mathrm{eff}}=35 \pm 5 \mu \mathrm{m}$, in good agreement with the climatological values proposed by Bozzo et al. (2008). The mean correction factor for the data set shown in this paper was $7 \%$.

\section{Cross-calibration}

Since no radiometric calibration is available for mini-DOAS, simultaneous measurements of SMART and mini-DOAS are used to cross-calibrate the mini-DOAS with SMART. The cross-calibration relies on the radiometric calibration of SMART and allows us to derive calibrated $I_{\mathrm{mD}}$ from miniDOAS measurements. Flight sections with inhomogeneous $\alpha$ and various cloud conditions are selected to obtain a calibration valid for a wide range of different $I$. Such conditions were present during the ML-CIRRUS flight on 26 March 2014, including measurements over southern Germany, Belgium, the United Kingdom, Ireland and the northern Atlantic Ocean west of Ireland. The cross-calibration is performed for the nadir and sideward viewing scanning telescopes of the mini-DOAS when aligned to the same cloud area as SMART. The results are presented for two wavelengths at $\lambda=1180 \mathrm{~nm}$ and $\lambda=1600 \mathrm{~nm}$ which are frequently used in cloud retrievals and show the best discrimination potential for small $\tau$ as presented in the sensitivity study. Different FWHMs of both spectrometer systems are considered by convoluting the spectrally higher resolved measurements of the mini-DOAS with the corresponding FWHM of the SMART spectrometer $(8-19 \mathrm{~nm})$.

\subsection{Nadir radiance}

The nadir sensors of the mini-DOAS operate in a fixed position, thus providing a large data set of simultaneous measurements with SMART. The time stamps of both instruments are corrected for temporal offsets in the data acquisition. Scatter plots of $I_{\mathrm{S}, \lambda}^{\mathrm{N}}$ and mini-DOAS raw data are shown in Fig. 8a and c for both wavelengths. For each data point a linear regression following Theil (1992) and Sen (1968) is performed. Using the method of Theil and Sen, the influence of outliers on the regression is reduced and the linear calibration equation $I_{\mathrm{S}, \lambda}^{\mathrm{N}}=a_{0} \cdot N_{\mathrm{mD}, \lambda}^{\mathrm{N}}+a_{1}$ for the miniDOAS radiances is determined. $I_{\mathrm{S}, \lambda}^{\mathrm{N}}$ is the radiance measured by SMART, $N_{\mathrm{mD}, \lambda}^{\mathrm{N}}$ the raw signal of mini-DOAS and $a_{0}$ and $a_{1}$ the calibration coefficients. The linear regressions are indicated by the gray lines in Fig. 8a and c. For the MLCIRRUS flight on 26 March 2014 the nadir geometry calibration coefficients are determined as $a_{0}=0.31 \mathrm{~mW} \mathrm{~m}^{-2} \mathrm{sr}^{-1}$ and $a_{1}=0.55 \mathrm{~mW} \mathrm{~m}^{-2} \mathrm{sr}^{-1}$ for $\lambda=1180 \mathrm{~nm}$ with an uncer- 

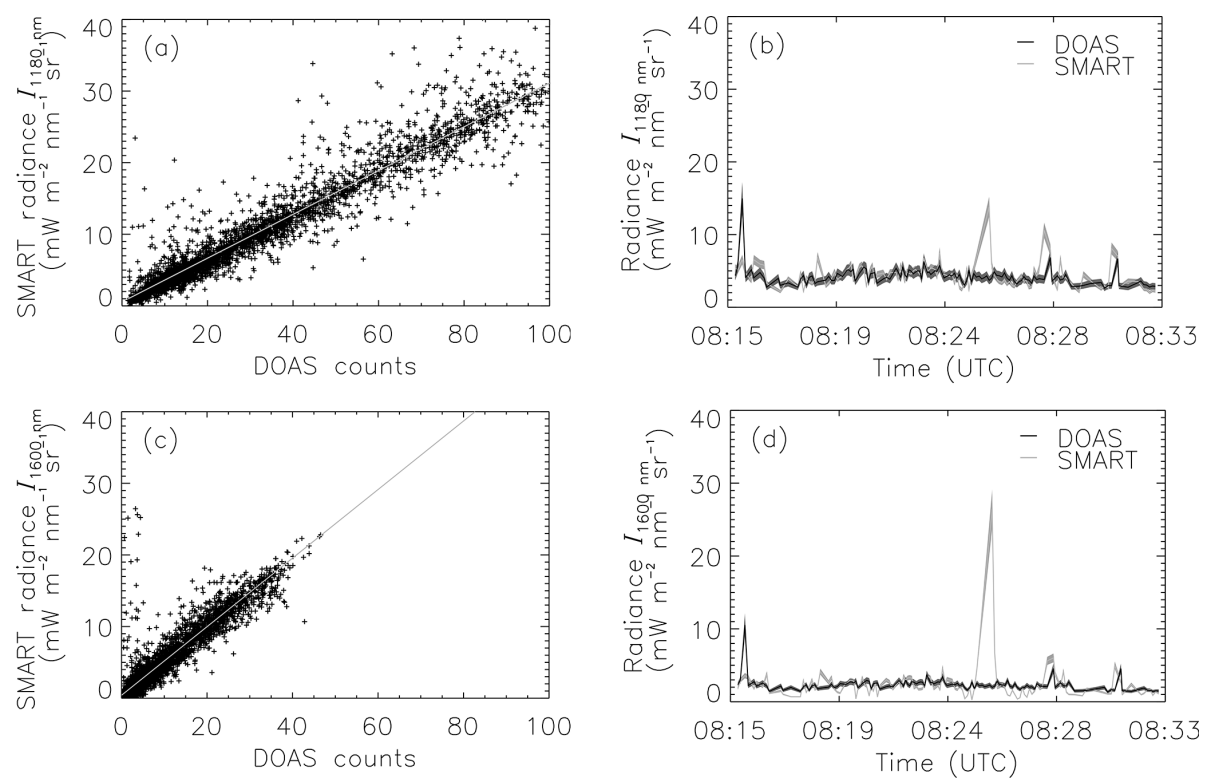

Figure 8. Panels (a) and (c) show comparisons of SMART radiance $I_{\mathrm{S}}^{\mathrm{N}}$ and mini-DOAS raw signal for nadir channels at $\lambda=1180 \mathrm{~nm}$ and $\lambda=1600 \mathrm{~nm}$ wavelength. Panels $(\mathbf{b})$ and $(\mathbf{d})$ show time series of measured SMART radiance $I_{\mathrm{S}, \lambda}^{\mathrm{N}}$ and calibrated mini-DOAS radiance $I_{\mathrm{mD}, \lambda}^{\mathrm{N}}$ for the ML-CIRRUS flight on 26 March 2014. The shaded areas indicate the measurement uncertainties.

tainty of $\pm 0.24 \mathrm{~mW} \mathrm{~m}^{-2} \mathrm{sr}^{-1}$. Similar calibrations are performed for flights during the NARVAL and ACRIDICONCHUVA campaigns. All calibration coefficients are summarized in Table 3. The coefficients depend on various environmental conditions where the temperature dependence of the mini-DOAS spectrometers is the most influential parameter.

The uncertainty is mostly related to differences in the fieldof-view (FOV) and the related difference in the observed scene and possible minor mismatches of the nadir orientation of both sensors. This means that both sensors do not always observe the exact same cloud area. For the $\lambda=1600 \mathrm{~nm}$ wavelength, $a_{0}$ is higher compared to $\lambda=1180 \mathrm{~nm}$ in all analyzed flights, indicating the different spectral sensitivities of both sensors with SMART in comparison with miniDOAS, being relatively more sensitive at $\lambda=1600 \mathrm{~nm}$ than at $\lambda=1180 \mathrm{~nm}$ wavelength.

The derived cross-calibrations of mini-DOAS are applied to all mini-DOAS measurements. A measurement example of a time series of calibrated mini-DOAS radiances $I_{\mathrm{mD}, \lambda}^{\mathrm{N}}$ is shown in Fig. 8b and d for an 18 min flight section measured on 26 March 2014.

The radiance time series for $\lambda=1180 \mathrm{~nm}$ of both sensors agree within the SMART error range for most data points, except for some radiance peaks. These differences likely result from the different FOV of both instruments and the presence of patches of low cumulus with high reflectivity. A similar result is obtained for $\lambda=1600 \mathrm{~nm}$. The differences in the mean radiance between both instruments for the time period presented in Fig. 8 are $0.75 \mathrm{~mW} \mathrm{~m}^{-2} \mathrm{~nm}^{-1} \mathrm{sr}^{-1}$ at $\lambda=1180 \mathrm{~nm}$ and $0.5 \mathrm{~mW} \mathrm{~m}^{-2} \mathrm{~nm}^{-1} \mathrm{sr}^{-1}$ at $\lambda=1600 \mathrm{~nm}$, which results in relative differences of $5.4 \%$ at $\lambda=1180 \mathrm{~nm}$ and $1.9 \%$ at $\lambda=1600 \mathrm{~nm}$ compared to the SMART absolute values.

\subsection{Sideward viewing radiance}

The scanning telescopes of the mini-DOAS typically run in a sequential mode scanning different $\theta_{\mathrm{v}}$. During selected flight segments the scanning sequences are configured to include nadir measurements. Due to this sequential mode less measurements from the sideward viewing channels are available for cross-calibration with SMART because only measurements in nadir sensor orientation are applicable for the cross-calibration. To ensure a statistically sufficient number of samples, the entire flight of 26 March 2014 is analyzed applying the same methods used for the calibration of the nadir channels. Figure 9a and c show the cross-calibration of SMART radiances $I_{\mathrm{S}, \lambda}^{\mathrm{N}}$ and mini-DOAS raw data $N_{\mathrm{mD}, \lambda}^{\mathrm{V}}$ and the linear fit (gray line) used for calibration.

For the IR scanning channels the calibration coefficients are determined as $a_{0}=0.31 \mathrm{~mW} \mathrm{~m}^{-2} \mathrm{sr}^{-1}$ with no offset $a_{1}$ for $\lambda=1180 \mathrm{~nm}$ and an uncertainty of $\pm 0.2 \mathrm{~mW} \mathrm{~m}^{-2} \mathrm{sr}^{-1}$. Similar to the nadir channels, the calibration coefficients for the the sideward viewing channel at $\lambda=1600 \mathrm{~nm}$ wavelength with $a_{0}=0.47$ are higher compared to the $\lambda=1180 \mathrm{~nm}$ wavelength.

The calibration of the sideward viewing channels is repeated for the NARVAL flights, while for all ACRIDICONCHUVA flights no nadir observations of the sideward viewing channels are available. Table 3 provides a summary of all calibration coefficients derived for the sideward viewing channels. 
Table 3. Calibration coefficients $a_{0}$ and $a_{1}$ in units of $\mathrm{mW} \mathrm{m}^{-2} \mathrm{~nm}^{-1} \mathrm{sr}^{-1}$ for mini-DOAS nadir and scanning channel radiance obtained for NARVAL (19 December 2013), ML-CIRRUS (26 March 2014) and ACRIDICON-CHUVA (9, 12 and 23 September 2014).

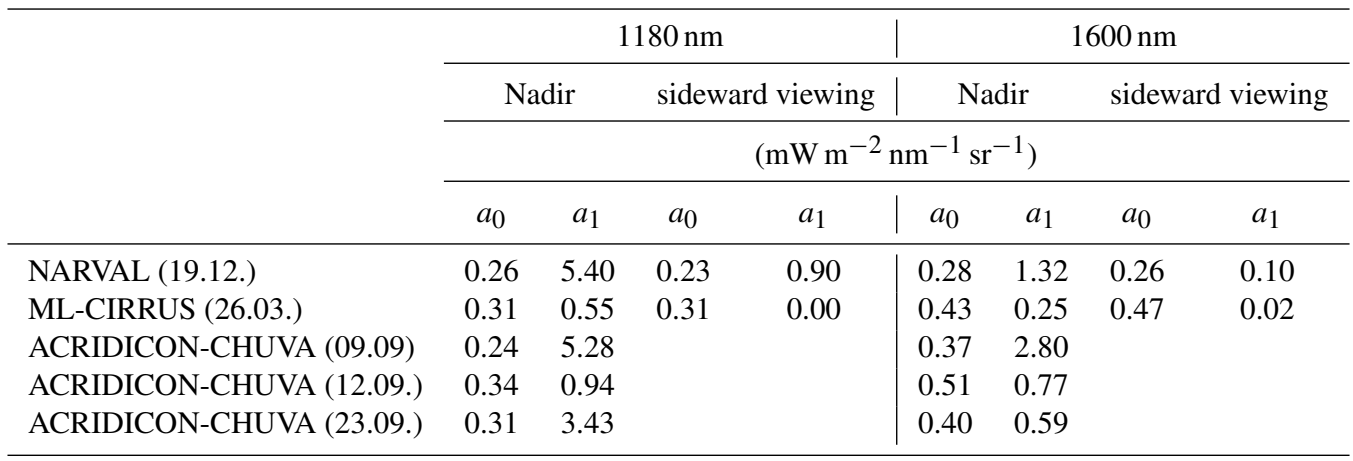
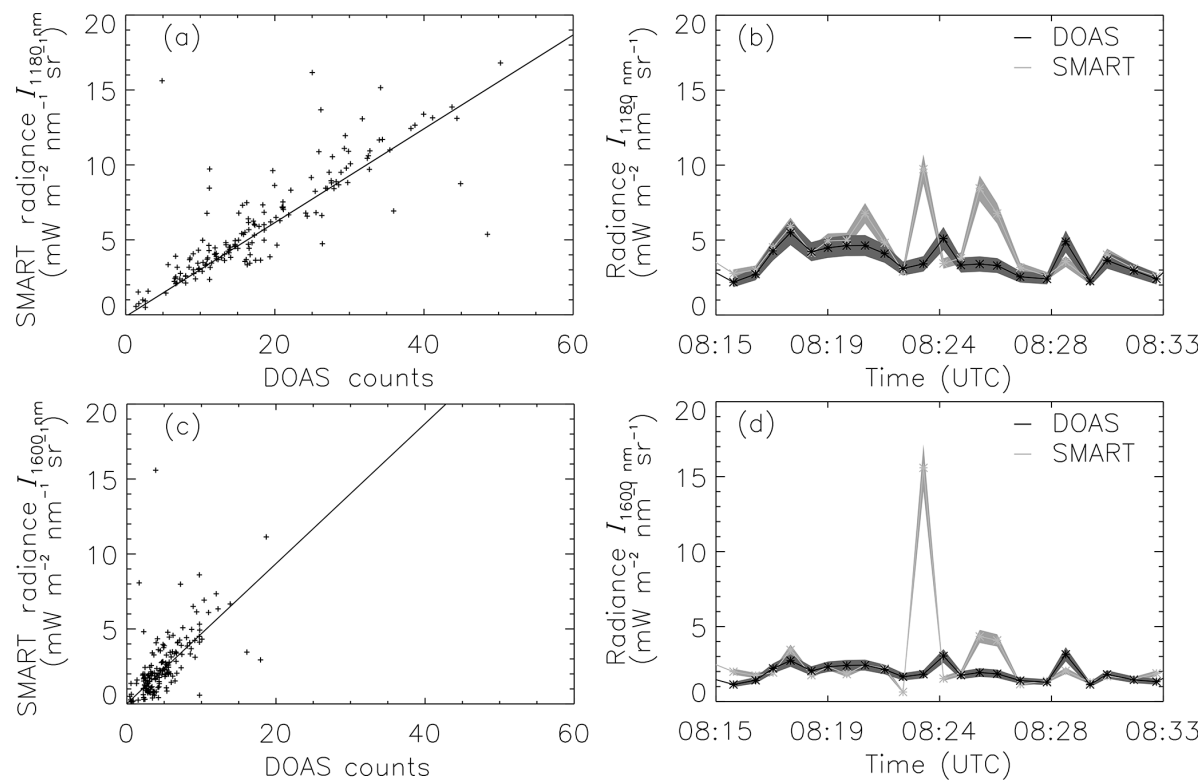

Figure 9. Panels (a) and (c) show a comparison of SMART radiance $I_{\mathrm{S}, \lambda}^{\mathrm{N}}$ and mini-DOAS raw signal $N_{\mathrm{mD}, \lambda}^{\mathrm{V}}$ for the scanning channels at $\lambda=1180 \mathrm{~nm}$ and $\lambda=1600 \mathrm{~nm}$ wavelength. Panels $(\mathbf{b})$ and (d) show time series of measured SMART radiance $I_{\mathrm{S}, \lambda}^{\mathrm{N}}$ and calibrated miniDOAS radiance $I_{\mathrm{mD}, \lambda}^{\mathrm{V}}$ for the ML-CIRRUS flight on 26 March 2014. The shaded areas indicate the measurement errors.

Similarly to Fig. 8b and d, Fig. $9 \mathrm{~b}$ and d show time series of SMART radiance $I_{\mathrm{S}, \lambda}^{\mathrm{N}}$ and calibrated mini-DOAS nadir observations of $I_{\mathrm{mD}, \lambda}^{\mathrm{V}}$ with the sideward viewing channels for an 18 min flight segment of ML-CIRRUS on 26 March 2014. In general, the radiance pattern observed by SMART is represented by the calibrated mini-DOAS radiance. However, individual data points differ due to differences in FOV, resulting in mean differences of $0.78 \mathrm{~mW} \mathrm{~m}^{-2} \mathrm{~nm}^{-1} \mathrm{sr}^{-1}$ at $1180 \mathrm{~nm}$ and $0.38 \mathrm{~mW} \mathrm{~m}^{-2} \mathrm{~nm}^{-1} \mathrm{sr}^{-1}$ at $\lambda=1600 \mathrm{~nm}$, which results in relative differences of $3.7 \%$ at $\lambda=1180 \mathrm{~nm}$ and $2.4 \%$ at $\lambda=1600 \mathrm{~nm}$ compared to the SMART absolute values. This ranges below the uncertainty range of SMART.

\subsection{Temporal stability of cross-calibration}

The mini-DOAS instrument is not explicitly designed to maintain a stable radiometric calibration but more for a stable wavelength calibration. For DOAS measurements absolute values of $I$ are not needed as only relative intensities are used. More important is the wavelength accuracy to determine absorption and emission bands of gasses precisely. As a result the radiometric calibration of the mini-DOAS can change from campaign to campaign and even between several flights. Therefore, cross-calibration coefficients for different campaigns and flights are derived to consider these changes in radiometric calibration and the optical setup, for example when changing the optical fibers. Using different calibration factors for the mini-DOAS instrument as inferred 


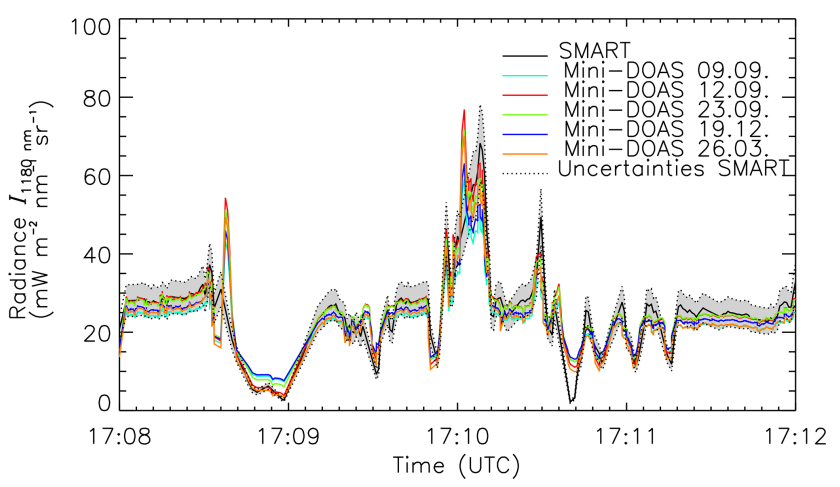

Figure 10. Time series of the nadir radiance of SMART $I_{\mathrm{S}, 1180}^{\mathrm{N}}$ and of the mini-DOAS $I_{\mathrm{mD}, 1180}^{\mathrm{N}}$ nadir channel at $\lambda=1180 \mathrm{~nm}$ using different calibrations as indicated in the legend. The uncertainty range of SMART radiance is shaded gray.

for the different campaigns, Fig. 10 shows a comparison of measured $I$ at $\lambda=1180 \mathrm{~nm}$ wavelength from a 4 min long flight segment over the Amazon region on 12 September 2014. The comparison clearly indicates that the measurements of $I$ of both sensors are not systematically biased and agree within the errors of each sensor except when differences at small spatial scales appear resulting from the different FOV.

The deviation of the different calibrations is below $2.9 \mathrm{~mW} \mathrm{~m}^{-2} \mathrm{~nm}^{-1} \mathrm{sr}^{-1}$ which is inside the measurement uncertainties of SMART and indicates a reasonable stability of the calibrations.

\section{Retrieval of cirrus optical thickness}

\subsection{Iterative algorithm}

By using all three calibrated radiance data sets obtained from SMART $I_{\mathrm{S}}^{\mathrm{N}}$, mini-DOAS nadir channels $I_{\mathrm{mD}}^{\mathrm{N}}$, and sideward viewing channels $I_{\mathrm{mD}}^{\mathrm{V}}$, an iterative retrieval algorithm of $\tau$ is developed and applied. It is based on the bi-spectral reflectance method described by Twomey and Seton (1980) and Nakajima and King (1990). Here, the retrieval is adapted for ice clouds with respect to ice crystal shape and used wavelengths, e.g., by Ou et al. (1995) and Rolland et al. (2000). To retrieve $\tau$, rough aggregates are assumed using pre-calculated ice crystal parameterizations following Yang et al. (2013). The iterative algorithm utilizes the spectral reflectivity $\mathcal{R}_{\lambda}$, which is defined as the ratio of spectral upward $I_{\lambda}$ to spectral downward $F_{\lambda}^{\downarrow}$,

$\mathcal{R}_{\lambda}=\frac{I_{\lambda} \pi}{F_{\lambda}^{\downarrow}}$

For the ML-CIRRUS data, $F_{\lambda}^{\downarrow}$ is taken from the actual SMART measurements on HALO. Measured $F_{\lambda}^{\downarrow}$ allows us to identify and eliminate any influence of the radiation field above the aircraft, for example by cirrus. As an alternative to pre-calculating look-up-tables (LUTs) by extensive forward simulations, an iterative algorithm is applied that runs RTS adjusted to each single measurement. This allows us to set up simulations by actual input parameters for each measurement, e.g., $\theta_{0}, \phi$, longitude, latitude and flight altitude. In that way, uncertainties caused by inaccurate assumptions in the RTS input are minimized. Additionally, the iterative method is not limited to a specific pre-calculated grid of $\tau$ and $r_{\text {eff }}$ as used in LUTs where a certain interval of preselected $\tau$ and $r_{\text {eff }}$ is given. The iterative algorithm automatically adjusts the range of $\tau$ and $r_{\text {eff }}$ without interpolation until it reaches the final result.

Figure 11 shows a scheme of the retrieval algorithm, which starts with an initial guess of $\tau_{0}$. Using the initial guess of $\tau$ and of any other cloud parameters, the cloud reflectivity $\mathcal{R}_{\text {sim }}$ is simulated and compared to the measurements $\mathcal{R}_{\text {meas }}$ of SMART and mini-DOAS, respectively. The ratio between $\mathcal{R}_{\text {sim, } \mathrm{n}}$ and $\mathcal{R}_{\text {meas }}$ derived for each iteration step $n$ is used to scale the particular guess $\tau_{\mathrm{n}}$ by

$\tau_{n+1}=\tau_{n} \cdot \frac{\mathcal{R}_{\text {sim }}}{\mathcal{R}_{\text {meas }}}$.

The adjusted $\tau_{n+1}$ is used in the RTS for the new iteration step $n+1$. The iteration of $\tau$ is repeated until the change in $\tau_{n}$ between two iteration steps is smaller than $5 \%$ or a limit of $n>100$ iteration steps is reached. These stop criteria determine the accuracy of the iterative retrieval. If a lower relative stop criterion (change in $\tau_{n}$ smaller than $5 \%$ between two iteration steps or more then 100 iteration steps) is used, the iteration may come closer to the true searched value and the retrieval accuracy increases as well as the necessary iteration steps and the computational time. To limit the computational time, the second stop criteria is used to limit the maximum number of iteration steps. For a typical cirrus observed during ML-CIRRUS with an average $\tau$ of 0.32 , the cirrus optical thickness can be retrieved with a accuracy of about $\tau \pm 0.03$. The retrieval of $\tau$ by SMART and mini-DOAS bases on the measurements at $\lambda=1180 \mathrm{~nm}$ and is scaled to $\lambda=532 \mathrm{~nm}$ to consider the wavelength dependence of $\tau$ and to be able to compare it with WALES measurement at $\lambda=532 \mathrm{~nm}$. Therefore, the retrieval considers RTS at both wavelengths. In the RTS $\tau$ is defined and changed at $\lambda=532 \mathrm{~nm}$ while the measurements are compared to simulations at $\lambda=1180 \mathrm{~nm}$ to determine the correct solution.

In case of measurements of optically thin cirrus, the retrieval can be applied for $\tau$ only. For these situations $I_{\mathrm{RTS}, 1600}^{\mathrm{N}}$ at $\lambda=1600 \mathrm{~nm}$ wavelength (ice absorption band) is too low and only measured with high uncertainty to retrieve $r_{\text {eff. }}$ For a cirrus cloud with $\tau=0.03$, the simulated upward nadir radiance $I_{\mathrm{RTS}, 1600}^{\mathrm{N}}$ and the sideward viewing radiance $I_{\mathrm{RTS}, 1600}^{\mathrm{V}}$ in the range of $0.2 \mathrm{~mW} \mathrm{~m}^{-2} \mathrm{sr}^{-1}$. Such low $I$ are in the range of the electronic noise of the spectrometers, leading to a low signal-to-noise ratio and high retrieval uncertainties. 


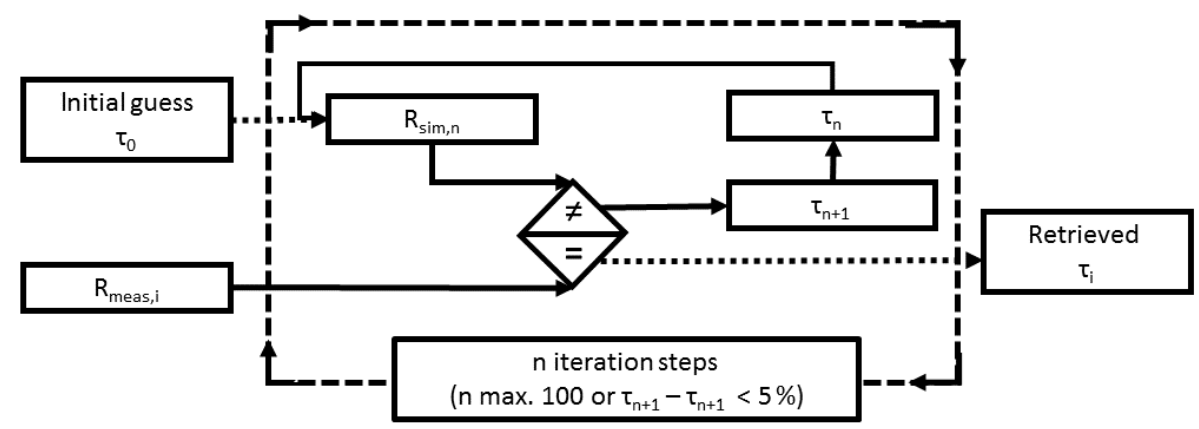

Figure 11. Scheme of the iterative algorithm. For every single measurement $i$ an iteration loop is started with an initial guess $\tau_{0}$ until measured $\mathcal{R}_{\text {meas }}$ and simulated $\mathcal{R}_{\text {sim }}$ reflectivity converge within $5 \%$ difference or a maximum of 100 iteration steps is reached. At the end of the process the result is saved.

Especially for cirrus with low $\tau$ the variation of $I_{\mathrm{RTS}, 1600}^{\mathrm{N}}$ and $I_{\mathrm{RTS}, 1600}^{\mathrm{V}}$ with respect to changes in $r_{\text {eff }}$ is low.

Simulations show that for $\tau=0.5$ the difference in $I_{\mathrm{RTS}, 1600}^{\mathrm{N}}$ in the nadir direction is only $0.1 \mathrm{~mW}$ when changing $r_{\text {eff }}$ from $10 \mu \mathrm{m}$ to $20 \mu \mathrm{m}$, indicating the low sensitivity of $r_{\text {eff }}$ retrievals at this wavelength. Therefore, a reliable retrieval of $r_{\text {eff }}$ with reasonable accuracy is not feasible. For $I_{\mathrm{RTS}, 1600}^{\mathrm{V}}$ the difference is $1.4 \mathrm{~mW} \mathrm{~m}^{-2} \mathrm{sr}^{-1}$ and about a magnitude larger, indicating that a retrieval of $r_{\text {eff }}$ might be reasonable. However, in order to be consistent between both nadir and sideward viewing retrieval, $r_{\text {eff }}$ has been fixed. A value of $r_{\text {eff }}=30 \mu \mathrm{m}$ was chosen, a typical value of ice crystals observed by in situ measurements during ML-CIRRUS (Voigt et al., 2016). Therefore, the influence of an invalid assumption of $r_{\text {eff }}$ on the iterative retrieval is analyzed. For this purpose the retrieval is tested for a typical cirrus of $\tau=0.3$ and is run with three different assumptions of $r_{\text {eff }}$ of 20,30 and $40 \mu \mathrm{m}$, representing the uncertainty of $r_{\text {eff. }}$. These simulations imply that the retrieved $\tau$ changes only by \pm 0.02 between smallest and largest $r_{\text {eff }}$, resulting in a relative error in $\tau$ of $6.7 \%$. The uncertainty in measured $I_{\mathrm{S}, 1600}^{\mathrm{N}}$ and $I_{\mathrm{mD}, 1600}^{\mathrm{V}}$ causes a retrieval uncertainty of less than $\tau \pm 0.2$. This justifies the fixed choice of $r_{\text {eff }}$ in this specific cloud case.

However, the dependence of retrieved $\tau$ and the assumption of $r_{\text {eff }}$ may vary with $\alpha$, ice crystal size, $\tau$ and $\lambda$ used in the retrieval.

\subsection{ML-CIRRUS case study}

The iterative retrieval is applied for a selected leg of the MLCIRRUS flight on 26 March 2014. For this day the Terra MODIS image (overpass time 10:40 UTC) indicates clouds, with a west to east gradient in $\tau$ ranging from 5.8 to 0.38 (Fig. 12) including small cloud free regions. For large areas, cirrus with $\tau \leq 1$ is indicated by MODIS providing provides a well suited test case to compare sideward viewing and nadir observations even when $\tau$ ranges above the SVC level. As discussed in Sect. 2, for low $\tau$ ranging up to $1, \varepsilon_{\tau}$ of sideward viewing observations is higher than for nadir observations.

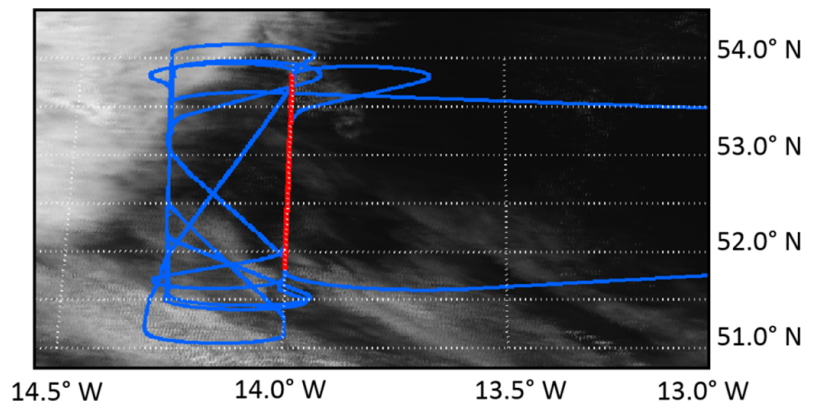

Figure 12. Investigated cloud field observed by MODIS-Terra on 26 March 2014. The flight track of HALO is indicated by the blue line. The flight leg between 08:15 and 08:36 UTC for which the cirrus retrieval is performed is indicated by the red line.

An advantage of using a test case with $\tau$ higher than SVC is the insensitivity of the retrieval uncertainty with respect to the radiance measurement uncertainty. The reflected $I$ is still sufficiently large and exceeds the noise level of the nadir looking instruments to make a comparison between nadir and sideward viewing instruments possible.

In Figure 12 the flight track of HALO is indicated by the blue line. The cloud retrieval is applied to the HALO flight segment for the leg between 08:15 and 08:36 UTC (highlighted in red) when HALO did fly above the cirrus. During this period the aircraft flew constantly at $12.6 \mathrm{~km}$ height from south to north along $14^{\circ} \mathrm{W}$. Due to low horizontal advection and hence slow cloud formation it can be expected that the Terra MODIS image (Fig. 12) will actually reflect the cloud cover investigated by HALO. The cirrus developed along a warm conveyor belt and contained embedded contrails as indicated by the lidar backscatter profiles at $\lambda=1064 \mathrm{~nm}$ and $\lambda=532 \mathrm{~nm}$ of WALES (see Fig. 13).

The time period for which $\tau$ is retrieved is marked by the black frame. The selected flight segment is characterized by a constant cloud top height and a slightly increasing cloud bottom height towards northern flight direction. While the upper most cloud top is relatively homogeneous, there is sig- 


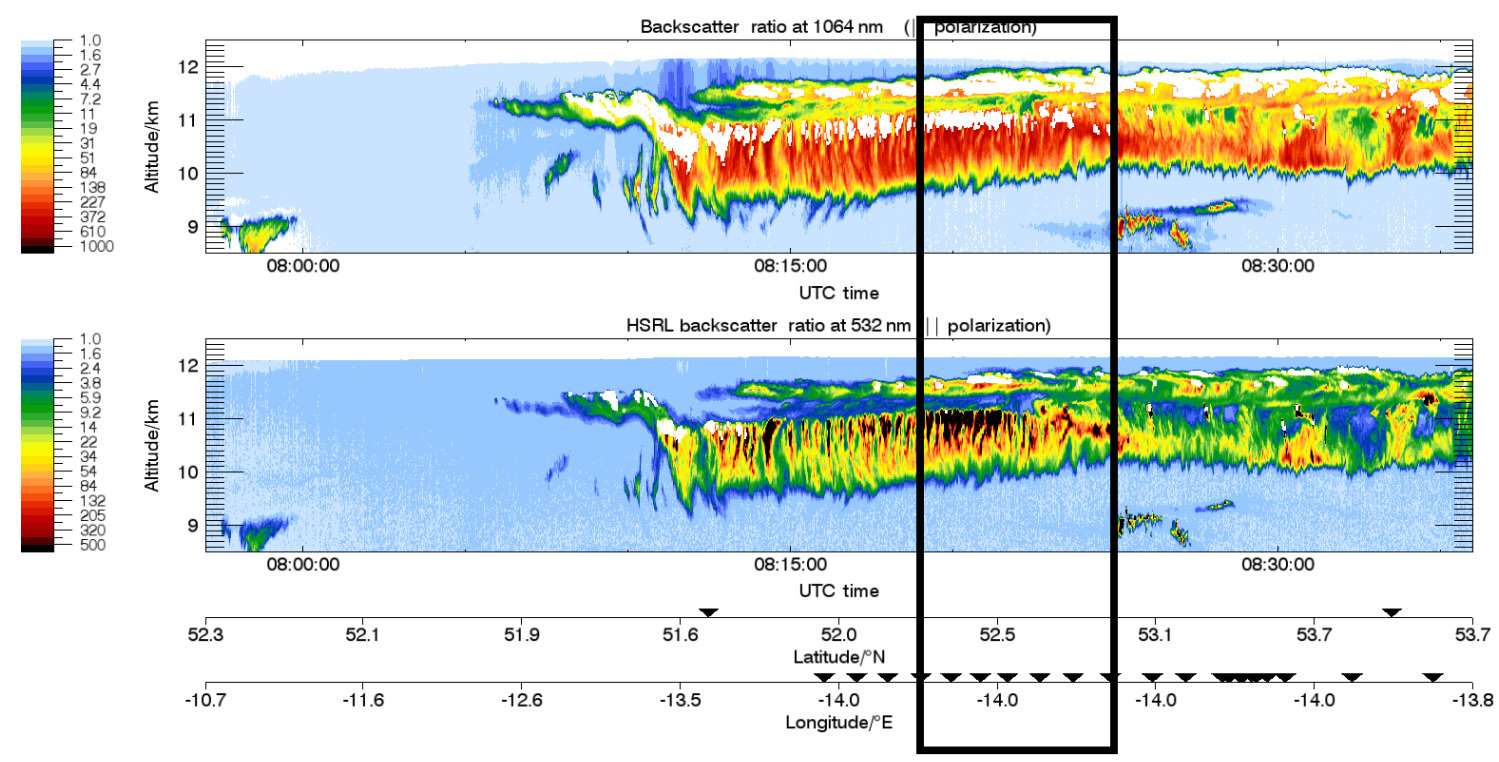

Figure 13. Vertical profiles of backscatter ratios at $\lambda=1064 \mathrm{~nm}$ (upper panel) and $\lambda=532 \mathrm{~nm}$ (lower panel) measured by WALES between 07:50 and 08:50 UTC. The time period for which $\tau$ is retrieved is marked by the black rectangle.

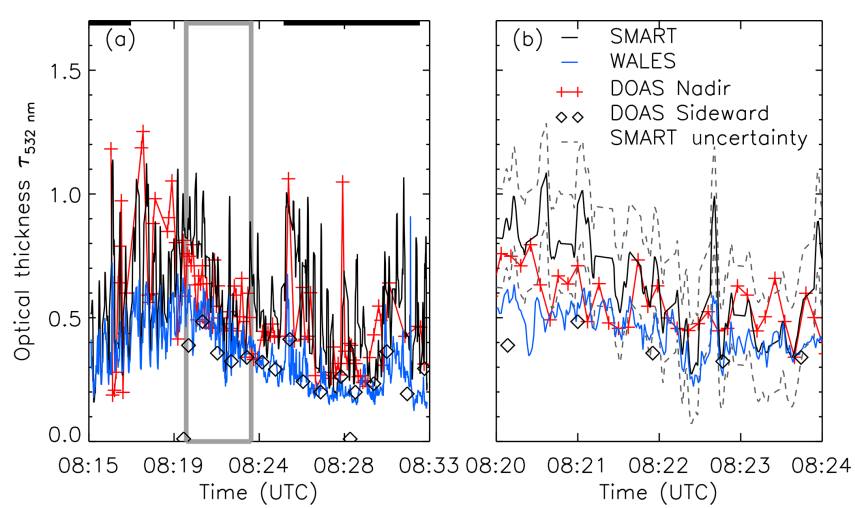

Figure 14. Time slices of the investigated flight segment on 26 March 2014 (a) and zoom (b) of $\tau$ at $\lambda=532 \mathrm{~nm}$ retrieved from SMART (black line), WALES (gray line), mini-DOAS sideward viewing (diamonds) and nadir spectrometers (crosses) along the flight track of ML-CIRRUS flight on 26 March 2014. Periods with the second cloud layer are marked by the black lines at the top of (a).

nificant variability in the layer below which is visible in the backscatter profile of WALES. The beginning of the black marked area shows high backscatter ratios of up to 500 indicating high reflectivity of a dense cirrus. At the end of the selected time period the backscatter decreases. The lower part of the cirrus shows small-scale variability mainly connected to sedimentation of ice crystals.

\subsubsection{Time series of cirrus optical thickness}

Figure 14a shows a 20 min long flight segment of retrieved $\tau$ at $\lambda=532 \mathrm{~nm}$ calculated from SMART, mini-DOAS nadir and sideward viewing spectrometers. WALES measurements are included for comparison. Along the analyzed cirrus, the retrieved $\tau$ ranges between 0.1 and 1.3, indicating the horizontal variability of the cirrus. The general decrease in $\tau$ towards higher latitudes (increasing time) matches with the cloud pattern observed by WALES. While SMART and miniDOAS nadir channels resolve the cirrus variability observed by WALES, the sideward viewing channel retrieval does not cover these fluctuations due to the reduced time resolution of the scanning mode and the large spatial scale (tens of kilometers) over which sideward viewing measurements average. At some locations, e.g., 08:21 UTC, $\tau$ retrieved by SMART and mini-DOAS significantly exceed the measurements of WALES. Most likely both instruments retrieve larger $\tau$ than WALES since ice crystals were falling out of the cirrus obscured to the lidar measurements. A second segment with higher retrieved $\tau$ is likely due to an underlying cirrus between 8.5 and $9.5 \mathrm{~km}$ altitude that is also obscured to the detection by WALES. Therefore, a positive systematic offset of the retrieved $\tau$ occurs for SMART and mini-DOAS. These data points are excluded from the following analysis. Nevertheless, there is a slight chance that a few cloud fragments of these second cloud layers are still affecting the SMART and mini-DOAS retrievals. Both passive sensors have a larger FOV compared to WALES and, therefore, are more likely sensitive to cloud layers located below the cirrus.

Average $\tau$ are calculated for the filtered time period (indicated by the gray box in Fig. 14) for each instrument. 
Due to different sampling intervals, a different resolution and number of observations are included in the averaging calculations. The retrieved averages of $\tau$ at $532 \mathrm{~nm}$ are $0.54 \pm 0.2$ (SMART), $0.49 \pm 0.2$ (mini-DOAS nadir spectrometer), $0.27 \pm 0.2$ (mini-DOAS sideward viewing spectrometer) and $0.32 \pm 0.02$ (WALES). The results indicate a reasonable agreement of $\tau$ retrieved by SMART and the mini-DOAS nadir channel, while lower $\tau$ are inferred from mini-DOAS sideward viewing and WALES measurements. Taking the WALES measurements as a reference, the measurements of SMART and mini-DOAS overestimate $\tau$. However, by estimating the uncertainty of the mini-DOAS and SMART based on RTS, the measurement error of $I_{\mathrm{S}, 1180}^{\mathrm{N}}$ $(14.5 \%)$ by SMART results in an uncertainty range of retrieved $\tau$ of \pm 0.2 , which covers the values of $\tau$ obtained by WALES. The uncertainty range of $\tau$ is determined by running the retrieval twice with a bias of measured $I_{\mathrm{S}, 1180}^{\mathrm{N}}$ with $\pm 14.5 \%$ uncertainty at $1180 \mathrm{~nm}$ wavelength as the upper and lower borders. The resulting upper and lower retrieved $\tau$ represent the retrieval uncertainty. The mean $\tau$ inferred from the mini-DOAS sideward viewing observations is significantly lower than measured by SMART and mini-DOAS nadir measurements. Differences in $\tau$ range up to \pm 0.73 between SMART and mini-DOAS sideward viewing observations. This may result from the different FOV of the sideward viewing geometry that does not observe the exact same clouds as SMART and nadir channels did. With the scanning sensors orientated to starboard, the sideward viewing retrieval corresponds to cirrus $8 \mathrm{~km}$ east of the flight track. As the MODIS satellite image in Fig. 12 indicates, the cirrus becomes slightly thinner towards the east, which possibly is due to the lower values of $\tau$. Other potential reasons are the assumed ice crystal shapes for the RTS and different fields-of-view of the passive and active remote sensing instruments. On the other hand, the agreement between mini-DOAS sideward observations and WALES is significantly better. The maximum difference in $\tau$ between miniDOAS sideward channels and WALES is \pm 0.25 , while the difference between the mean values is \pm 0.05 (15.6\%). With WALES and mini-DOAS measuring in different viewing geometries but showing better agreement, the differences in $\tau$ retrieved by SMART are most likely caused by uncertainties in $\alpha$. As discussed in Sect. 2.3, nadir observations are more strongly affected by $\alpha$ than by sideward observations. This is confirmed by the smaller differences between WALES and mini-DOAS sideward observations and indicates the advantage of the sideward viewing retrieval due to a reduced surface influence and lower retrieval uncertainty.

Figure $14 \mathrm{~b}$ displays a zoom of the time series between 08:20 to 08:24 UTC. During this flight segment, $\tau$ inferred by WALES is characterized by systematic oscillations varying between 0.2 and 1.1 also visible in the backscatter profile of WALES in Fig. 13. The lag time between two maxima is approximately between 20 and $25 \mathrm{~s}$ flight time, which corresponds to a horizontal distance between 4.4 and $5.5 \mathrm{~km}$. This pattern is present in the measurements of SMART, WALES and the mini-DOAS nadir channels even though partly obscured in the latter measurements due to its reduced time and space resolution.

Figure 15a to $d$ show scatter plots of retrieved $\tau$ for the different instrument combinations. A linear regression through the origin is performed and displayed in all cases. Data where a second cloud layer was present below the cirrus (gray points) are excluded. The comparison between SMART and WALES in Fig. 15a shows that the majority of the data is below the $1: 1$ line (gray). The linear regression results in $f(x)=0.6621 \times x$. The regression confirms that SMART systematically retrieves higher $\tau$ compared to WALES.

Compared to SMART, mini-DOAS nadir observations of $\tau$ depart less from WALES (Fig. 15b. Similar to SMART, the slope of the linear fit $f(x)=0.6943 \times x$ indicates that miniDOAS systematically overestimates $\tau$ compared to WALES. This similarity between SMART and mini-DOAS is obvious as SMART and mini-DOAS rely on the same radiometric calibration and retrieval. As indicated in Fig. 14b retrieved $\tau$ from WALES and the mini-DOAS sideward viewing channels agree well confirmed by the linear regression in Fig. 15c that gives a slope of $f(x)=1.0328 \times x$ close to unity. The overestimation of retrieved $\tau$ by the mini-DOAS nadir channels compared to the sideward channels is visible in Fig. $14 \mathrm{~d}$ which results in a linear fit of $f(x)=1.642 \times x$.

Overall the comparison provides evidence that the inferred $\tau$ agrees between the different sensors.

Having nadir and sideward viewing observations at the same time allows us to select the appropriate measurement geometry depending on the cloud situation, e.g., $\tau$ and $\alpha$. The sensitivity studies in Sect. 2.4 suggest that a combination of nadir and sideward viewing measurements allows a retrieval of $\tau$ for a wide range of cirrus clouds depending on the observation conditions. For thin clouds the sideward viewing geometry would be preferred. In case the cloud becomes optically too thick, leading to high upward $I_{\mathrm{S}, 1180}^{\mathrm{V}}$ and a saturation of $\varepsilon_{\tau}$, no retrievals of $\tau$ are possible. Then, switching to nadir observations of $I_{\mathrm{S}, 1180}^{\mathrm{N}}$ still enables us to determine the amount of reflected radiation and to retrieve $\tau$.

\subsubsection{Probability distribution of cirrus optical thickness}

For further comparison the probability density functions (PDFs) of $\tau$ retrieved by SMART, mini-DOAS nadir spectrometers and WALES were investigated. A PDF of miniDOAS sideward viewing spectrometers is not included because of the limited number of data points, making a statistically meaningful PDF impossible. The PDFs are shown in Fig. 16. Corresponding mean and median values of the distributions are given in Table 4. SMART (black solid line) and mini-DOAS (red solid line), which are based on the same radiometric calibration and retrieval method, show a comparable PDF, indicating that both instruments measured the 

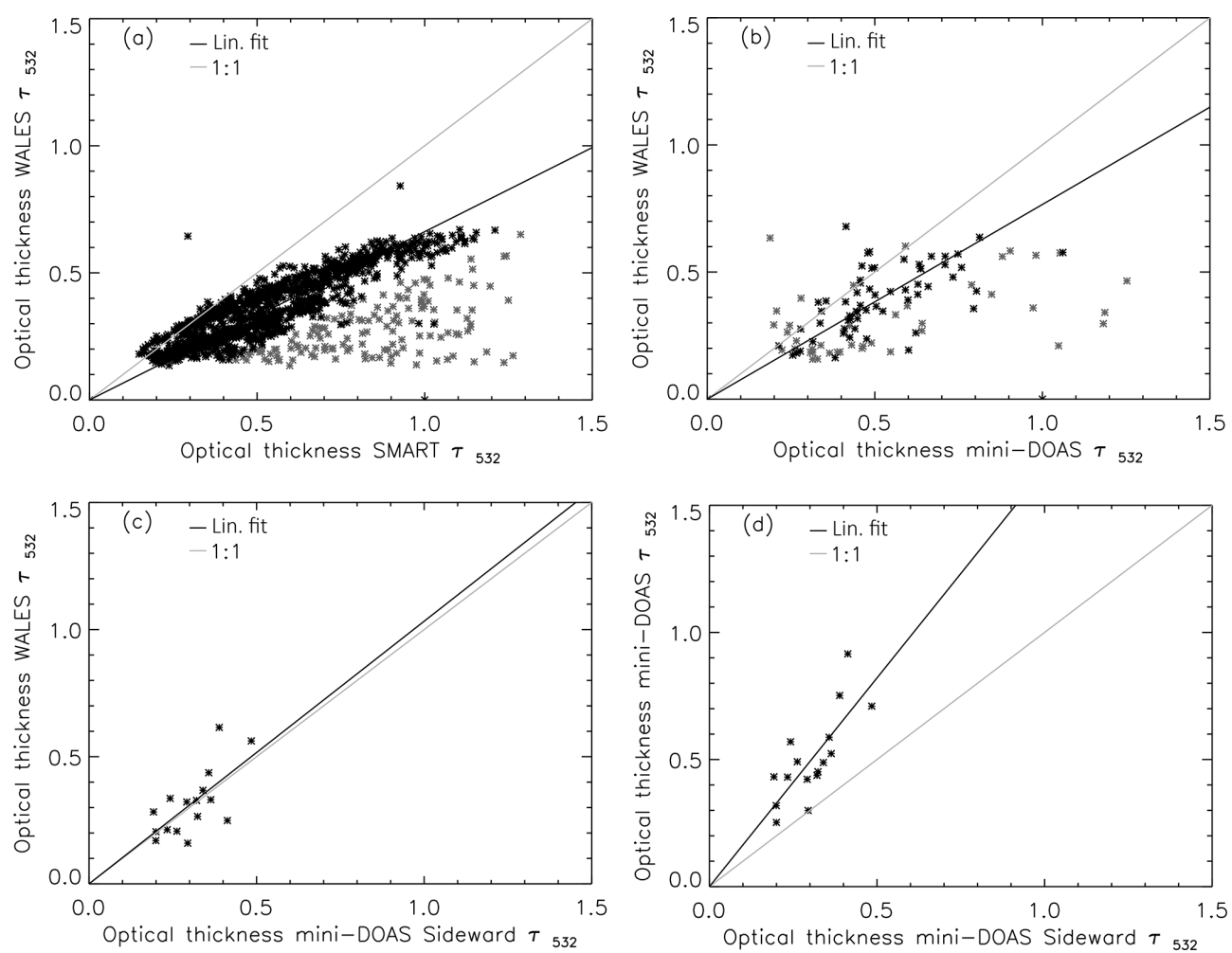

Figure 15. (a) Comparison of the retrieved cirrus optical thickness $\tau$ by WALES and SMART at $\lambda=532$ nm wavelength. (b) Comparison of the retrieved cirrus optical thickness $\tau$ by WALES and the mini-DOAS nadir channel at $\lambda=532 \mathrm{~nm}$ wavelength. Measurements when a second cirrus layer was present are displayed in gray and are discarded in the regression. (c) Comparison of the retrieved cirrus optical thickness $\tau$ by WALES and mini-DOAS sideward viewing channels at $\lambda=532 \mathrm{~nm}$ wavelength. No data are discarded. (d) Comparison of the retrieved cirrus optical thickness $\tau$ by mini-DOAS nadir and sideward viewing channels at $\lambda=532$ nm wavelength.

same cloud area. In both cases observed $\tau$ range from 0.15 to 1.25 for SMART and mini-DOAS and from 0.15 to 0.7 for WALES (black dashed line). The PDF maxima for SMART and mini-DOAS are around $\tau=0.4$, and are slightly more pronounced for mini-DOAS. For SMART and mini-DOAS, the PDFs are skewed to small $\tau$, with a median of 0.47 for SMART and 0.48 for mini-DOAS. This is slightly smaller than the mean values of 0.5 for SMART and 0.51 for miniDOAS. Both PDFs are long-tailed towards large $\tau$, slowly decreasing to higher values of $\tau$. In contrast, $\tau$ measured by WALES (black dashed line) show a stronger shift to low $\tau$, as the mean value of $\tau$ is significantly lower. The most frequent $\tau$ is around 0.2. The WALES measurements do not show $\tau$ larger than 0.7. This results in a stronger decrease in the WALES PDF to higher $\tau$ compared to SMART and mini-DOAS. The difference may be explained by a different FOV and therefore measuring of different horizontal parts of the clouds. It is assumed that SMART and mini-DOAS, e.g., due to a similarly large FOV, average over larger areas and are influenced by 3-D radiative effects caused by clouds, atmosphere and surface, which are not considered in the presented 1-D RTS and the iterative retrieval (Davis et al., 1997). In contrast, WALES has a more narrow FOV resulting from
Table 4. Mean and median of the PDFs of cirrus optical thickness $\tau$ derived from WALES, SMART and mini-DOAS.

\begin{tabular}{lcc}
\hline & mean & median \\
\hline WALES & 0.35 & 0.33 \\
SMART & 0.56 & 0.52 \\
mini-DOAS & 0.52 & 0.47 \\
\hline
\end{tabular}

an opening angle of the telescope of $0.08^{\circ}$. Because of the smaller FOV of WALES, the spot of the laser at the cloud top covers a smaller area compared to SMART and mini-DOAS, which have a spatial resolution in the range of tens of meters, depending on the distance between aircraft and cloud top. Therefore, WALES resolves finer cloud structures that may exhibit lower $\tau$ (cloud gaps) or larger $\tau$. In case of the most unfortunate situation, WALES would measure a cloud free region but SMART and mini-DOAS would receive $I^{\mathrm{N}}$ from a much larger area including clouds with various $\tau$. This better spatial resolution of WALES to SMART and mini-DOAS may explain the shift of WALES to lower $\tau$, but does not give reasons for the lower amount of high $\tau$. 
Differences in the PDF of $\tau$ may also result from the measurement methodologies. While WALES uses a laser with small FOV for active remote sensing, SMART and miniDOAS are passive remote instruments relaying on scattered sunlight. Therefore, SMART and mini-DOAS are influenced by the RTS of the whole atmosphere, while WALES is only sensitive to scattering within its narrow LOS. Additionally, the different wavelengths of the measurements may introduce biases in the retrieved $\tau$ due to different penetration depth of the reflected radiation into the cloud (Platnick, 2000). Therefore, the wavelength selection defines the layer in the cloud which is probed. While WALES uses backscatter measurements at $\lambda=532 \mathrm{~nm}$ and $\lambda=1064 \mathrm{~nm}$ the measurements of $I_{\mathrm{S}, 1180}$ by SMART and mini-DOAS are performed at $\lambda=1180 \mathrm{~nm}$. Although the retrieval accounts for the wavelength dependence of scattering, absorption and refraction on ice crystals (Takano and Liou, 1989; Yang et al., 2013) by scaling the retrieved $\tau$ at $\lambda=1180 \mathrm{~nm}$ to $\lambda=532 \mathrm{~nm}$ to make it comparable between the different instruments.

Referring to the sensitivity studies from Sect. 2 the influence of $\alpha$ and the ice crystal shape effects on the upward $I$ measured in nadir geometry is larger compared to the sideward viewing measurements. While nadir observations, especially of optical thin clouds, are strongly influenced by $\alpha$, sideward viewing observations are less effected. This is demonstrated in this case study where the sea surface albedo may vary due to different surface wind speeds (Cox and Munk, 1954) and indicates the advantage of sideward viewing measurements. An other possible reason for the differences in the PDF and the mean values between mini-DOAS nadir and sideward retrievals of $\tau$ are the varying angular dependencies of measured $I$ for different ice crystal shapes. For the RTS in the retrieval an assumption for the ice crystal shape has to be made which slightly influences the result for the nadir retrieval. This is more pronounced for the retrieval using the sideward channels of the mini-DOAS which is presented in the sensitivity study in Sect. 2.2. The WALES measurements are less effect by different ice crystal shapes but more on the ice crystal size assumption which is a general difference between the active and remote sensing instruments presented here.

\section{Conclusions}

The potential of airborne spectral radiance measurements in the sideward viewing direction for cirrus remote sensing is investigated. For this purpose radiative transfer simulations (RTS) are performed and airborne measurements of the Spectral Modular Airborne Radiation measurement sysTem (SMART) and the Differential Optical Absorption Spectrometer (mini-DOAS) are compared. A sensitivity study based on RTS showed that sideward viewing measurements are generally more suited for detecting and investigating opti-

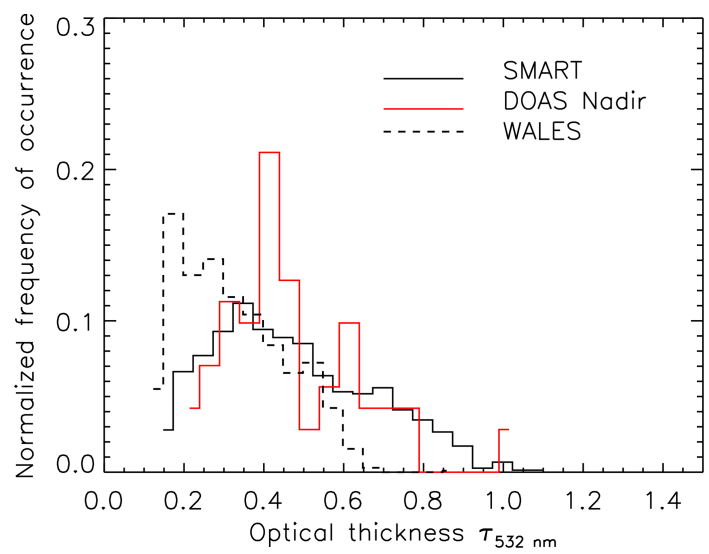

Figure 16. PDFs of cirrus optical thickness $\tau$ at $\lambda=532 \mathrm{~nm}$ retrieved from SMART, mini-DOAS and WALES measurements. The bin size is 0.05 units of $\tau$.

cally thin cirrus than observations in the nadir direction. Using sideward viewing observations, the sensitivity $\varepsilon_{\tau}$ of measured radiance $I^{\mathrm{V}}$ is larger than for nadir measurements up to a factor of 10, depending on the selected observation geometry and cloud properties. For cirrus optical thickness $\tau \leq 1$ and all simulated sideward viewing geometries $\varepsilon_{\tau}$ is larger compared to nadir observations. This results in a higher retrieval accuracy due to a reduced influence of measurement uncertainties. The RTS indicate that large observation angles $\theta_{\mathrm{V}}$ (close to the horizon) and small relative solar azimuth angles $\phi$ (observations in the direction of the Sun) result in the highest $\varepsilon_{\tau}$.

For retrievals of $\tau$ using sideward viewing measurements, the wavelength selection is crucial. Simulations indicate that wavelengths larger than $\lambda=900 \mathrm{~nm}$ are best suited. Reflected $I^{\mathrm{V}}$ of smaller wavelengths is significantly contaminated by scattering and absorption due to the reducing interference from Rayleigh scattering. Furthermore, the sideward viewing orientation reduces the influence of the surface albedo $\alpha$ on reflected $I^{\mathrm{V}}$. As a result, a precise assumption of $\alpha$ in the retrieval algorithm is less crucial. This substantially improves the uncertainties of passive solar remote sensing especially in locations of highly variable $\alpha$, where an exact assumption of $\alpha$ is impossible.

Contrarily, for sideward observations, a reasonably good assumption of the ice crystal shape used in the RTS is important. The RTS showed that in sideward viewing geometry the shape effects on reflected $I^{\mathrm{V}}$ are more pronounced than for nadir measurements. An incorrect assumption would bias the retrieval of $\tau$ significantly. On the other hand, the sensitivity for different ice crystal shapes may offer the possibility of retrieving shape information when measuring at different viewing angles. Nevertheless, smoothing of horizontal variability of optical thickness fields by sideward viewing observations has to be taken into account. 
Using the SMART, mini-DOAS nadir and sideward measurements in conjunction with an iterative retrieval, $\tau$ is derived for a case study of ML-CIRRUS. The inferred $\tau$ from SMART, mini-DOAS and the additional lidar measurement by the Water Vapour Lidar Experiment in Space (WALES) show a reasonable good agreement in $\tau$ for the nadir channels, with absolute differences of $\pm 0.22(66.6 \%)$ between SMART and WALES and $\pm 0.17(52.3 \%)$ between mini-DOAS and WALES observations, respectively. The retrieval using mini-DOAS sideward channels is also successful demonstrated for a reduced set of observations limited to $\theta_{\mathrm{V}}$ between 85 and $90^{\circ}$. Differences in $\tau$ range up to \pm 0.73 between SMART and mini-DOAS sideward viewing observations and are partly caused by the different viewing geometries. First, the sideward telescopes view in the starboard direction, probing the cirrus cloud top at approximately $8000 \mathrm{~m}$ aside the flight track. Second, the nadir observations may suffer from uncertainties in $\alpha$ while the sideward observations are less effected by changes in $\alpha$. Even for sea surfaces as presented here, $\alpha$ may change due to different wind speeds. Other potential reasons are the assumed ice crystal shapes in the RTS and different fields-of-view of the passive and active remote sensing instruments. This conclusion is apparent from different probability distributions. While SMART and mini-DOAS show a median around $\tau=0.4$, the median for WALES is shifted to lower $\tau$ around 0.2 , indicating that WALES observed small $\tau$ more frequently. The difference in mean values of $\tau$ between mini-DOAS sideward channels and WALES is smaller with $\pm 0.05(15.6 \%)$. This shows the advantage of the sideward viewing retrieval due to a reduced surface influence and lower retrieval uncertainty, because of high $\varepsilon_{\tau}$ compared to the nadir measurements. For future dedicated cloud observations it is recommended to adjust $\theta_{\mathrm{V}}$ to the most sensitive direction between 60 and $90^{\circ}$ to reduce the uncertainty in the sideward viewing retrieval. Additional sideward viewing scans in homogeneous cloud conditions might be used to estimate the cirrus ice crystal shape and minimize the retrieval uncertainties. The case study shows that cirrus retrievals using airborne sideward viewing observations with mini-DOAS are possible and can increase the potential of remote sensing on HALO significantly. Therefore, we suggest sideward viewing measurements for passive remote sensing of optically thin cirrus clouds.

Data availability. The data products of the ML-CIRRUS, NARVAL and ACRIDICON campaigns are available at the HALO database (https://halo-db.pa.op.dlr.de/mission/2). To get access to the data and information, please contact the corresponding author or the responsible co-authors.

Competing interests. The authors declare that they have no conflict of interest.
Acknowledgements. This research was funded by the German Research Foundation (DFG, HALO-SPP 1294). The authors acknowledge the support by the Deutsche Forschungsgemeinschaft (DFG) through grants PF 384/7-1/2, PF 384/16-1 and WE 1900/35-1. The authors thank the pilots and appreciate the support by the Flugbereitschaft of the German Aerospace Center (DLR). Additionally the authors thank enviscope $\mathrm{GmbH}$ for preparation and testing of SMART.

Edited by: D. Baumgardner

Reviewed by: two anonymous referees

\section{References}

Abrams, M. C., Chang, A. Y., Gunson, M. R., Abbas, M. M., Goldman, A., Irion, F. W., Michelson, H. A., Newchurch, M. J., Rinsland, C. P., Stiller, G. P., and Zander, R.: On the assessment and uncertainty of atmospheric trace gas burden measurements with high resolution infrared solar occultation spectra from space by the ATMOS Experiment, Geophys. Res. Lett., 23, 2337-2340, doi:10.1029/96GL01794, 1996

Baum, B. A., Heymsfield, A. J., Yang, P., and Bedka, S. T.: Bulk scattering properties for the remote sensing of ice clouds. Part I: Microphysical data and models, J. Appl. Meteorol., 44, 18851895, 2005.

Bierwirth, E., Wendisch, M., Ehrlich, A., Heese, B., Tesche, M., Althausen, D., Schladitz, A., Müller, D., Otto, S., Trautmann, T., Dinter, T., von Hoyningen-Huene, W., and Kahn, R.: Spectral surface albedo over Morocco and its impact on the radiative forcing of Saharan dust, Tellus, 61B, 252-269, 2009.

Bierwirth, E., Wendisch, M., Jakel, E., Ehrlich, A., Schmidt, K. S., Stark, H., Pilewskie, P., Esselborn, M., Gobbi, G. P., Ferrare, R., Muller, T., and Clarke, A.: A new method to retrieve the aerosol layer absorption coefficient from airborne flux density and actinic radiation measurements RID E-7433-2010, J. Geophys. Res., 115, D14211, doi:10.1029/2009JD013636, 2010.

Bourassa, A. E., Degenstein, D. A., and Llewellyn, E. J.: Climatology of the subvisual cirrus clouds as seen by OSIRIS on Odin, Adv. Space Res., 36, 807-812, doi:10.1016/j.asr.2005.05.045, 2005.

Bozzo, A., Maestri, T., Rizzi, R., and Tosi, E.: Parameterization of single scattering properties of mid-latitude cirrus clouds for fast radiative transfer models using particle mixtures, Geophys. Res. Lett., 35, L16809, doi:10.1029/2008GL034695, 2008.

Brückner, M., Pospichal, B., Macke, A., and Wendisch, M.: A new multispectral cloud retrieval method for ship-based solar transmissivity measurements, J. Geophys. Res.-Atmos., 119, 1133811354, doi:10.1002/2014JD021775, 2014

Chen, T., Rossow, W., and Zhang, Y.: Radiative effects of cloudtype variations, J. Climate, 13, 264-286, 2000.

Clark, R. N., Swayze, G. A., Wise, R., Livo, E., Hoefen, T., Kokaly, R., and Sutley, S. J.: USGS digital spectral library splib06a, Tech. rep., US Geological Survey, http://speclab.cr.usgs.gov/ spectral-lib.html (last access: 16 April 2016), 2007.

Clerbaux, C., Hadji-Lazaro, J., Turquety, S., Mégie, G., and Coheur, P.-F.: Trace gas measurements from infrared satellite for chemistry and climate applications, Atmos. Chem. Phys., 3, 14951508, doi:10.5194/acp-3-1495-2003, 2003. 
Comstock, J. M., Ackerman, T. P., and Mace, G. G.: Ground-based lidar and radar remote sensing of tropical cirrus clouds at Nauru Island: Cloud statistics and radiative impacts, J. Geophys. Res., 107, 4714, doi:10.1029/2002JD002203, 2002.

Cox, C. and Munk, W.: Measurement of the roughness of the sea surface from photographs of the sun's glitter, J. Opt. Soc. Am. A., 44, 838-850, 1954.

Cziczo, D. J., Froyd, K. D., Hoose, C., Jensen, E. J., Diao, M., Zondlo, M. A., Smith, J. B., Twohy, C. H., and Murphy, D. M.: Clarifying the Dominant Sources and Mechanisms of Cirrus Cloud Formation, Science, 340, 1320-1324, doi:10.1126/science.1234145, 2013.

Davis, A., Marshak, A., Cahalan, R., and Wiscombe, W.: The Landsat scale break in stratocumulus as a three-dimensional radiative transfer effect: Implications for cloud remote sensing, J. Atmos. Sci., 54, 241-260, 1997.

Davis, S., Hlavka, D., Jensen, E., Rosenlof, K., Yang, Q. O., Schmidt, S., Borrmann, S., Frey, W., Lawson, P., Voemel, H., and Bui, T. P.: In situ and lidar observations of tropopause subvisible cirrus clouds during TC4, J. Geophys. Res., 115, D00J17, doi:10.1029/2009JD013093, 2010.

Delanoe, J., Protat, A., Jourdan, O., Pelon, J., Papazzoni, M., Dupuy, R., Gayet, J.-F., and Jouan, C.: Comparison of Airborne In Situ, Airborne Radar-Lidar, and Spaceborne RadarLidar Retrievals of Polar Ice Cloud Properties Sampled during the POLARCAT Campaign, J. Atmos. Ocean. Tech., 30, 57-73, doi:10.1175/JTECH-D-11-00200.1, 2013.

Ehret, G., Gross, S., Schäfler, A., Wirth, M., Fix, A., and Kiemle, C.: Characterization of Cirrus Cloud Properties by Airborne Differential Absorption and High Spectral Resolution Lidar Measurements, AGU Fall Meeting Abstracts, 2014.

Ehrlich, A., Bierwirth, E., Wendisch, M., Gayet, J.-F., Mioche, G., Lampert, A., and Heintzenberg, J.: Cloud phase identification of Arctic boundary-layer clouds from airborne spectral reflection measurements: test of three approaches, Atmos. Chem. Phys., 8, 7493-7505, doi:10.5194/acp-8-7493-2008, 2008.

Eichler, H., Ehrlich, A., Wendisch, M., Mioche, G., Gayet, J.F., Wirth, M., Emde, C., and Minikin, A.: Influence of ice crystal shape on retrieval of cirrus optical thickness and effective radius: A case study, J. Geophys. Res., 114, D19203, doi:10.1029/2009JD012215, 2009.

Eloranta, E. W.: Practical model for the calculation of multiply scattered lidar returns, Appl. Optics, 37, 2464-2472, doi:10.1364/AO.37.002464, 1998.

Esselborn, M., Wirth, M., Fix, A., Tesche, M., and Ehret, G.: Airborne high spectral resolution lidar for measuring aerosol extinction and backscatter coefficients, Appl. Optics, 47, 346-358, doi:10.1364/AO.47.000346, 2008.

Frey, W., Borrmann, S., Kunkel, D., Weigel, R., de Reus, M., Schlager, H., Roiger, A., Voigt, C., Hoor, P., Curtius, J., Krämer, M., Schiller, C., Volk, C. M., Homan, C. D., Fierli, F., Di Donfrancesco, G., Ulanovsky, A., Ravegnani, F., Sitnikov, N. M., Viciani, S., D’Amato, F., Shur, G. N., Belyaev, G. V., Law, K. S., and Cairo, F.: In situ measurements of tropical cloud properties in the West African Monsoon: upper tropospheric ice clouds, Mesoscale Convective System outflow, and subvisual cirrus, Atmos. Chem. Phys., 11, 5569-5590, doi:10.5194/acp-11-55692011, 2011 .
Fricke, C., Ehrlich, A., Jäkel, E., Bohn, B., Wirth, M., and Wendisch, M.: Influence of local surface albedo variability and ice crystal shape on passive remote sensing of thin cirrus, Atmos. Chem. Phys., 14, 1943-1958, doi:10.5194/acp-14-19432014, 2014.

Froyd, K. D., Murphy, D. M., Lawson, P., Baumgardner, D., and Herman, R. L.: Aerosols that form subvisible cirrus at the tropical tropopause, Atmos. Chem. Phys., 10, 209-218, doi:10.5194/acp10-209-2010, 2010.

$\mathrm{Fu}, \mathrm{Q}$. and Liou, K.: Parameterization of the radiative properties of cirrus clouds, J. Atmos. Sci., 50, 2008-2025, 1993.

$\mathrm{Fu}, \mathrm{Q} ., \mathrm{Hu}, \mathrm{Y}$., and Yang, Q.: Identifying the top of the tropical tropopause layer from vertical mass flux analysis and CALIPSO lidar cloud observations, Geophys. Res. Lett., 34, 114813, doi:10.1029/2007GL030099, 2007.

Gross, S., Forster, L., Wirth, M., Schäfler, A., Freudenthaler, V., Fix, A., and Mayer, B.: Characterization of mid-latitude cirrus cloud with airborne and ground-based lidar measurements during ML-CIRRUS, in: EGU General Assembly Conference Abstracts, vol. 17 of EGU General Assembly Conference Abstracts, p. $10283,2015$.

Gueymard, C. A.: The sun's total and spectral irradiance for solar energy applications and solar radiation models, Sol. Energy, 76, 423-453, 2004.

Hüneke, T.: The scaling method applied to HALO measurements: Inferring absolute trace gas concentrations from airborne limb spectroscopy under all sky conditions, $\mathrm{PhD}$ thesis, RupertoCarola University of Heidelberg, Germany, 2016.

IPCC: Climate Change 2013: The Physical Science Basis, Cambridge University Press, Cambridge, United Kingdom and New York, NY, USA, 2013.

Jensen, E. J., Pfister, L., Jordan, D. E., Bui, T. V., Ueyama, R., Singh, H. B., Thornberry, T., Rollins, A. W., Gao, R.-S., Fahey, D. W., Rosenlof, K. H., Elkins, J. W., Diskin, G. S., DiGangi, J. P., Lawson, R. P., Woods, S., Atlas, E. L., Rodriguez, M. A. N., Wofsy, S. C., Pittman, J., Bardeen, C. G., Toon, O. B., Kindel, B. C., Newman, P. A., McGill, M. J., Hlavka, D. L., Lait, L. R., Schoeberl, M. R., Bergman, J. W., Selkirk, H. B., Alexander, M. J., Kim, J.-E., Lim, B. H., Stutz, J., and Pfeilsticker, K.: The NASA Airborne Tropical TRopopause EXperiment (ATTREX): High-Altitude Aircraft Measurements in the Tropical Western Pacific, B. Am. Meteorol. Soc., 98, 129-143, doi:10.1175/BAMS-D-14-00263.1, 2015.

Kärcher, B.: Properties of subvisible cirrus clouds formed by homogeneous freezing, Atmos. Chem. Phys., 2, 161-170, doi:10.5194/acp-2-161-2002, 2002.

King, M. D., Platnick, S., Yang, P., Arnold, G. T., Gray, M. A., Riedi, J. C., Ackerman, S. A., and Liou, K. N.: Remote sensing of liquid water and ice cloud optical thickness and effective radius in the Arctic: Application of airborne multispectral MAS data, J. Atmos. Ocean. Tech., 21, 857-875, 2004.

Klepp, C., Ament, S., Bakan, S., Hirsch, L., and Stevens, B.: NARVAL Campaign Report, vol. 164, Reports on Earth System Science, Max Planck Institute for Meteorology Hamburg, Germany, 2014.

Lampert, A., Ehrlich, A., Dörnbrack, A., Jourdan, O., Gayet, J.F., Mioche, G., Shcherbakov, V., Ritter, C., and Wendisch, M.: Microphysical and radiative characterization of a subvisible midlevel Arctic ice cloud by airborne observations - a case study, 
Atmos. Chem. Phys., 9, 2647-2661, doi:10.5194/acp-9-26472009, 2009.

Lee, J., Yang, P., Dessler, A. E., Gao, B.-C., and Platnick, S.: Distribution and radiative forcing of tropical thin cirrus clouds, J. Atmos. Sci., 66, 3721-3731, doi:10.1175/2009JAS3183.1, 2009.

Mayer, B. and Kylling, A.: Technical note: The libRadtran software package for radiative transfer calculations - description and examples of use, Atmos. Chem. Phys., 5, 1855-1877, doi:10.5194/acp-5-1855-2005, 2005.

McFarquhar, G. M., Heymsfield, A. J., Spinhirne, J., and Hart, B.: Thin and subvisual tropopause tropical cirrus: Observations and radiative impacts, J. Atmos. Sci., 57, 1841-1853, doi:10.1175/1520-0469(2000)057<1841:TASTTC>2.0.CO;2, 2000.

Nakajima, T. and King, M.: Determination of the optical thickness and effective particle radius of clouds from reflected solar radiation measurements. Part I: Theory, J. Atmos. Sci., 47, 18781893, 1990.

Oikarinen, L.: Effect of surface albedo variations on UV-visible limb-scattering measurements of the atmosphere, J. Geophys. Res., 107, ACH 13-1-ACH 13-15, doi:10.1029/2001JD001492, 2002.

Ou, S., Liou, K., Gooch, W., and Takano, Y.: Remote sensing of cirrus cloud parameters using advanced very-high-resolution radiometer 3.7- and 10.9- $\mu \mathrm{m}$ channels, Appl. Optics, 32, 21712180, 1993.

Ou, S., Liou, K.-N., Takano, Y., Rao, X., Fu, Q., Heymsfield, A., Miloshevich, L., Baum, B., and Kinne, S.: Remote sounding of cirrus cloud optical depths and ice crystal structures from AVHRR data: Verification using FIRE II IFO measurements, J. Atmos. Sci., 52, 4143-4158, 1995.

Pierluissi, J. and Peng, G.-S.: New molecular transmission band models for LOWTRAN, Opt. Eng., 24, 541-547, 1985.

Platnick, S.: Vertical photon transport in cloud remote sensing problems, J. Geophys. Res., 105, 22919-22935, 2000.

Platt, C.: Remote sounding of high clouds. III: Monte Carlo calculations of multiple-scattered lidar returns, J. Atmos. Sci., 38, 156-167, 1981.

Platt, U. and Stutz, J.: Differential Optical Absorption Spectroscopy: Principles and Applications, Series: Physics of Earth and Space Environments, Springer Verlag, ISBN 3540211934, 2008.

Pruppacher, H. and Klett, J.: Microphysics of Clouds and Precipitation, Kluwer Academic, Dordrecht, Boston, 1997.

Rolland, P. and Liou, K.: Surface variability effects on the remote sensing of thin cirrus optical and microphysical properties, J. Geophys. Res., 106, 22965-22977, doi:10.1029/2001JD900160, 2001

Rolland, P., Liou, K., King, M., Tsay, S., and McFarquhar, G.: Remote sensing of optical and microphysical properties of cirrus clouds using Moderate-Resolution Imaging Spectroradiometer channels: Methodology and sensitivity to physical assumptions, J. Geophys. Res., 105, 11721-11738, doi:10.1029/2000JD900028, 2000.

Sassen, K., Wang, Z., and Liu, D.: Cirrus clouds and deep convection in the tropics: Insights from CALIPSO and CloudSat, J. Geophys. Res.-Atmos., 114, 2156-2202, doi:10.1029/2009JD011916, 2009.
Sausen, R., Isaksen, I., Grewe, V., Hauglustaine, D., Lee, D., Myhre, G., Köhler, M., Pitari, G., Schumann, U., Stordal, F., and Zerefos, C.: Aviation radiative forcing in 2000: An update on IPCC (1999), Meteor. Z., 14, 555-561, 2005.

Schäfer, M., Bierwirth, E., Ehrlich, A., Heyner, F., and Wendisch, M.: Retrieval of cirrus optical thickness and assessment of ice crystal shape from ground-based imaging spectrometry, Atmos. Meas. Tech., 6, 1855-1868, doi:10.5194/amt-6-1855-2013, 2013.

Sen, P. K.: Estimates of the Regression Coefficient Based on Kendall's Tau, J. Am. Stat. Assoc., 63, 1379-1389, doi:10.1080/01621459.1968.10480934, 1968.

Shettle, E.: Models of aerosols, clouds and precipitation for atmospheric propagation studies, in: Atmospheric propagation in the uv, visible, ir and mm-region and related system aspects, no. 454 in AGARD Conference Proceedings, 1989.

Stamnes, K., Tsay, S.-C., Wiscombe, W., and Laszlo, I.: DISORT, a General-Purpose Fortran Program for Discrete-Ordinate-Method Radiative Transfer in Scattering and Emitting Layered Media: Documentation of Methodology, Tech. rep., Dept. of Physics and Engineering Physics, Stevens Institute of Technology, Hoboken, NJ 07030, 2000.

Takano, Y. and Liou, K.-N.: Solar radiative transfer in cirrus clouds. Part I: Single-scattering and optical properties of hexagonal ice crystals, J. Atmos. Sci., 46, 1-19, 1989.

Theil, H.: A Rank-Invariant Method of Linear and Polynomial Regression Analysis, in: Henri Theils Contributions to Economics and Econometrics, edited by: Raj, B. and Koerts, J., vol. 23 of Adv. S. Theo. App. Eco., Springer, the Netherlands, 345-381, doi:10.1007/978-94-011-2546-8_20, 1992.

Toon, O. B., Starr, D. O., Jensen, E. J., Newman, P. A., Platnick, S., Schoeberl, M. R., Wennberg, P. O., Wofsy, S. C., Kurylo, M. J., Maring, H., Jucks, K. W., Craig, M. S., Vasques, M. F., Pfister, L., Rosenlof, K. H., Selkirk, H. B., Colarco, P. R., Kawa, S. R., Mace, G. G., Minnis, P., and Pickering, K. E.: Planning, implementation, and first results of the Tropical Composition, Cloud and Climate Coupling Experiment (TC4), J. Geophys. Res.-Atmos., 115, D00J04, doi:10.1029/2009JD013073, 2010.

Twomey, S. and Seton, K. J.: Inferences of gross microphysical properties of clouds from spectral reflectance measurements, J. Atmos. Sci., 37, 1065-1069, 1980.

Voigt, C., Schumann, U., Jurkat, T., Schäuble, D., Schlager, H., Petzold, A., Gayet, J.-F., Krämer, M., Schneider, J., Borrmann, S., Schmale, J., Jessberger, P., Hamburger, T., Lichtenstern, M., Scheibe, M., Gourbeyre, C., Meyer, J., Kübbeler, M., Frey, W., Kalesse, H., Butler, T., Lawrence, M. G., Holzäpfel, F., Arnold, F., Wendisch, M., Döpelheuer, A., Gottschaldt, K., Baumann, R., Zöger, M., Sölch, I., Rautenhaus, M., and Dörnbrack, A.: In-situ observations of young contrails - overview and selected results from the CONCERT campaign, Atmos. Chem. Phys., 10, 90399056, doi:10.5194/acp-10-9039-2010, 2010.

Voigt, C., Schumann, U., Minikin, A., Abdelmonem, A., Afchine, A., Borrmann, S., Boettcher, M., Buchholz, B., Bugliaro, L., Costa, A., Curtius, J., Dollner, M., Dörnbrack, A., Dreiling, V., Ebert, V., Ehrlich, A., Fix, A., Forster, L., Frank, F., Fütterer, D., Giez, A., Graf, K., Grooß, J.-U., Groß, S., Heimerl, K., Heinold, B., Hüneke, T., Järvinen, E., Jurkat, T., Kaufmann, S., Kenntner, M., Klingebiel, M., Klimach, T., Kohl, R., Krämer, M., Krisna, T. C., Luebke, A., Mayer, M., Mertes, S., Molleker, S., Pet- 
zold, A., Pfeilsticker, K., Port, M., Rapp, M., Reutter, P., Rolf, C., Rose, D., Sauer, D., Schäfler, A., Schlage, R., Schnaiter, M., Schneider, J., Spelten, N., Spichtinger, P., Stock, P., Walser, A., Weigel, R., Weinzierl, B., Wendisch, M., Werner, F., Wernli, H., Wirth, M., Zahn, A., Ziereis, H., and Zöger, M.: ML-CIRRUS - The airborne experiment on natural cirrus and contrail cirrus with the high-altitude long-range research aircraft HALO, B. Am. Meteorol. Soc., 98, 271-288, doi:10.1175/BAMS-D-1500213.1, 2016.

Wang, P.-H., Minnis, P., McCormick, M. P., Kent, G. S., and Skeens, K. M.: A 6-year climatology of cloud occurrence frequency from Stratospheric Aerosol and Gas Experiment II observations (1985-1990), J. Geophys. Res.-Atmos., 101, $29407-$ 29429, doi:10.1029/96JD01780, 1996.

Wendisch, M., Müller, D., Schell, D., and Heintzenberg, J.: An airborne spectral albedometer with active horizontal stabilization, J. Atmos. Ocean. Tech., 18, 1856-1866, 2001.

Wendisch, M., Pilewskie, P., Pommier, J., Howard, S., Yang, P., Heymsfield, A. J., Schmitt, C. G., Baumgardner, D., and Mayer, B.: Impact of cirrus crystal shape on solar spectral irradiance: A case study for subtropical cirrus, J. Geophys. Res., 110, D03202, doi:10.1029/2004JD005294, 2005.

Wendisch, M., Yang, P., and Pilewskie, P.: Effects of ice crystal habit on thermal infrared radiative properties and forcing of cirrus, J. Geophys. Res., 112, D03202, doi:10.1029/2006JD007899, 2007.

Wendisch, M., Pöschl, U., Andreae, M. O., Machado, L. A. T., Albrecht, R., Schlager, H., Rosenfeld, D., Martin, S. T., Abdelmonem, A., Afchine, A., Araujo, A., Artaxo, R., Aufmhoff, H., Barbosa, H. M. J., Borrmann, S., Braga, R., Buchholz, B., Cecchini, M. A., Costa, A., Curtius, J., Dollner, M., Dorf, M., Dreiling, V., Ebert, V., Ehrlich, A., Ewald, F., Fisch, G., Fix, A., Frank, F., Fütterer, D., Heckl, C., Heidelberg, F., Hüneke, T., Jäkel, E., Järvinen, E., Jurkat, T., Kanter, S., Kästner, U., Kenntner, M., Kesselmeier, J., Klimach, T., Knecht, M., Kohl, R., Kölling, T., Krämer, M., Krüger, M., Krisna, T. C., Lavric, J. V., Longo, K., Mahnke, C., Manzi, A. O., Mayer, B., Mertes, S., Minikin, A., Molleker, S., Münch, S., Nillius, B., Pfeilsticker, K., Pöhlker, C., Roiger, A. E., Rose, D., Rosenow, D., Sauer, D., Schnaiter, M., Schneider, J., Schulz, C., de Souza, R. A. F., Spanu, A., Stock, P., Vila, D., Voigt, C., Walser, A., Walter, D., Weigel, R., Weinzierl, B., Werner, R., Yamasoe, M. A., Ziereis, H., Zinner, T., and Zöger, M.: The ACRIDICON-CHUVA campaign: Studying tropical deep convective clouds and precipitation over Amazonia using the new German research aircraft HALO, B. Am. Meteorol. Soc., 97, 1885-1908, doi:10.1175/BAMS-D-14-00255.1, 2016.
Wiensz, J. T., Degenstein, D. A., Lloyd, N. D., and Bourassa, A. E.: Retrieval of subvisual cirrus cloud optical thickness from limb-scatter measurements, Atmos. Meas. Tech., 6, 105-119, doi:10.5194/amt-6-105-2013, 2013.

Winker, D. M. and Trepte, C. R.: Laminar cirrus observed near the tropical tropopause by LITE, Geophys. Res. Lett., 25, 33513354, 1998.

Wirth, M., Fix, A., Mahnke, P., Schwarzer, H., Schrandt, F., and Ehret, G.: The airborne multi-wavelength water vapor differential absorption lidar WALES: System design and performance, Appl. Phys. B-Lasers O., 96, 201-213, 2009.

Woodbury, G. E. and McCormick, M. P.: Zonal and geographical distributions of cirrus clouds determined from SAGE data, J. Geophys. Res.-Atmos., 91, 2775-2785, doi:10.1029/JD091iD02p02775, 1986.

Yang, H. Y., Dobbie, S., Herbert, R., Connolly, P., Gallagher, M., Ghosh, S., Al-Jumur, S. M. R. K., and Clayton, J.: The effect of oberserved vertical structure, habits, and size distribution on the solar radiative properties and cloud evolution of cirrus clouds, Q. J. R. Meteor. Soc., 138, 1221-1232, 2012.

Yang, P., Bi, L., Baum, B. A., Liou, K. N., Kattawar, G. W., Mishchenko, M. I., and Cole, B.: Spectrall consistent scatterin, absorption, and polarization properties of atmospheric ice crystals at wavelengths from 0.2 to $100 \mu \mathrm{m}$, J. Atmos. Sci., 70, 330 347, 2013.

Zhang, Y., Macke, A., and Albers, F.: Effect of crystal size spectrum and crystal shape on stratiform cirrus radiative forcing, Atmos. Res., 52, 59-75, 1999. 